NBER WORKING PAPER SERIES

\title{
CONSEQUENCES OF ELIMINATING FEDERAL DISABILITY BENEFITS FOR SUBSTANCE ABUSERS
}

\author{
Pinka Chatterji \\ Ellen Meara
}

Working Paper 13407

http://www.nber.org/papers/w13407

\author{
NATIONAL BUREAU OF ECONOMIC RESEARCH \\ 1050 Massachusetts Avenue \\ Cambridge, MA 02138 \\ September 2007
}

We thank Max Kates for outstanding research assistance. We received helpful comments from seminar participants at the BU/Harvard/MIT Health Economics Seminar, the Davis Seminar at the University of Chicago, the University at Albany, and the 2007 International Health Economics Association Meetings. Meara gratefully acknowledges funding from NIDA to support this work. The views expressed herein are those of the author(s) and do not necessarily reflect the views of the National Bureau of Economic Research.

(C) 2007 by Pinka Chatterji and Ellen Meara. All rights reserved. Short sections of text, not to exceed two paragraphs, may be quoted without explicit permission provided that full credit, including $\odot$ notice, is given to the source. 
Consequences of Eliminating Federal Disability Benefits for Substance Abusers

Pinka Chatterji and Ellen Meara

NBER Working Paper No. 13407

September 2007, Revised October 2008

JEL No. I1,I28

\begin{abstract}
Using annual, repeated cross-sections from national household survey data, we estimate how the January 1997 termination of federal disability insurance, Supplemental Security Income (SSI) and Disability Insurance (DI), for those with Drug Addiction and Alcoholism affected labor market outcomes among individuals targeted by the legislation. We also examine whether the policy change affected health insurance, health care utilization, and arrests. We employ propensity score methods to address differences in observed characteristics between substance users and others, and we used a difference-in-difference-in-difference approach to mitigate potential omitted variables bias. In the short-run (1997-1999), declines in SSI receipt accompanied appreciable increases in labor force participation and current employment. There was little measurable effect of the policy change on insurance and utilization, but we have limited power to detect effects on these outcomes. In the long-run (1999-2002), the rate of SSI receipt returned to earlier levels, and short-run gains in labor market outcomes waned.
\end{abstract}

\author{
Pinka Chatterji \\ University at Albany \\ Economics Department \\ Business Administration 111A \\ 1400 Washington Avenue \\ Albany, NY 12222 \\ and NBER \\ pchatterji@albany.edu \\ Ellen Meara \\ Department of Health Care Policy \\ Harvard Medical School \\ 180 Longwood Avenue \\ Boston, MA 02115-5899 \\ and NBER \\ meara@hcp.med.harvard.edu
}




\section{Introduction}

At the heart of the debate about the government's role in providing economic support to individuals with substance disorders are opposing views about the relationship between substance use disorders (SUDs) and economic dependency. Some regard SUDs as any other disabling illness; by this view, afflicted persons may require government support in order to meet their basic needs (Rosenheck, Frisman, \& Gallup, 1995; Rossi, 1989; Sosin \& Grossman, 1991). An influential analysis documented striking similarities in the heritability and influence of environmental factors, the rate of adherence to recommended treatment, and relapse rates among those with drug dependence compared to patients with type II diabetes mellitus, hypertension, and asthma (McClellan et al. 2000). Others focus on the behavioral aspect of SUDs, and imply that public programs may foster economic dependency and even encourage substance use by providing resources that can be used to purchase substances and by reducing incentives to work (Cohen, 1994; Phillips, Christenfeld, \& Ryan, 1999; Shaner et al., 1995). Athough recent studies do not support this latter claim (Rosen, McMahon, Lin, \& Rosenheck, 2006; Swartz, Hsieh, \& Baumohi, 2003), the idea already has affected public policy. Most dramatically, in March 1996, the US Congress passed legislation barring persons with disabling substance disorders from receiving Supplemental Security Income (SSI) and Disability Insurance (DI) benefits. Prior to this change, which took effect in January 1997, about 209,000 individuals with substance disorders had been receiving SSI, DI, or both (Gresenz, Watkins, \& Podus, 1998).

Whether terminating public assistance benefits to individuals with substance disorders encourages economic independence, and whether loss of these benefits causes harm, remains a key concern among policymakers. Surprisingly, this fundamental question has not been answered by research, despite recent, major policy shifts in federal disability programs targeting individuals with substance disorders, and despite the backdrop of growing emphasis on personal responsibility towards all potential public assistance recipients (Davies et al., 2000). The goal of this paper is to estimate the effects of terminating federal disability benefits for individuals likely to have SUDs on labor market outcomes. We also examine effects of the policy change on health and criminal justice outcomes.

To estimate these effects, we pooled annual cross-sectional data from 1994-2002 in the 
National Household Survey on Drug Abuse (NHSDA) and the National Survey on Drug Use and Health (NSDUH). We define two alternative treatment groups, or likely substance abusers, based on substance use, symptoms of substance abuse or dependence, or recent use of substance abuse treatment. We use a modified difference-in-difference-in-difference (DDD) approach, comparing outcomes of substance abusers with a high probability of SSI use - to outcomes among non-substance-abusers with a high probability of SSI use, both before and after the policy change, netting out trends in outcomes during this time period that may have affected substance abusers and non-substance abusers with a low probability of SSI use. ${ }^{1}$ To make non-substance abusers more comparable to likely substance abusers in our sample, we used propensity scorebased weighting to balance the distribution of observable characteristics across these two groups. Our approach and data source allow us to augment and improve existing evidence on this policy change in several ways. Unlike prior studies of this policy change, we considered both short-run (1997-1998) and longer run (1999-2002) effects of the policy, we incorporate a comparison group for the group targeted by the policy change, and we assess a range of health, labor market, and social outcomes in a nationally representative sample of individuals.

Using this DDD approach combined with propensity score-based weighting, overall, our results show that individuals with substance problems did increase their economic selfsufficiency after the loss of public support benefits during the mid 1990's. This increase in selfsufficiency took place without measurable impact on insurance coverage and health services utilization, although we have limited power to detect effects for these outcomes. The gains were relatively short-lived among individuals reporting symptoms of substance abuse or dependence, among whom SSI receipt, employment, and labor force participation returned to levels closer to the pre-period rates after 1998.

In the short-run, 1997-98, the policy change accompanied higher participation in the labor force and current employment, and lower use of SSI among individuals likely to use SSI and likely to have substance abuse or dependence. In contrast to prior studies reporting a drop in Medicaid use, we found no significant changes in rates of health insurance coverage from any source or health services utilization. Welfare receipt changed little in the short-run. In the longrun, 1999-2002, rates of SSI receipt rebounded somewhat, but welfare use fell, and effects on

\footnotetext{
${ }^{1}$ In our empirical estimation described in section 3, we use a triple interaction between the continuous probability of SSI use, presence in the substance abuser group, and an indicator for post-policy change, rather than a strict DDD estimate using a discrete variable for high probability of SSI use.
} 
employment and labor force participation persisted among a broad group of likely substance abusers. Not surprisingly, labor force participation among individuals reporting symptoms of substance abuse or dependence fell in the long-run after increasing in 1997-98. We find no long run differential trend in health insurance status and utilization. Finally, we find suggestive evidence that arrest rates rose within the targeted groups following the policy change, particularly during the longer term period (1999-2002).

Section II of the paper describes changes in public support programs affecting individuals with SUDs and the evidence to date on the consequences of the elimination of SSI/DI for drug abuse and alcoholism. Section III describes our empirical strategy. Section IV describes the data used, Section V presents the results of our analyses, and Section VI discusses conclusions and implications from our results.

\section{Changes in public programs affecting individuals with SUDs}

\section{A. Elimination of Federal Disability Benefits for Substance Abusers}

The federal SSI and DI programs are public income assistance programs for the disabled. Low income elderly, blind, and disabled persons can qualify for SSI payments, while DI provides federal disability insurance, and more generous cash payments to covered workers. Disabled workers must have a sufficient earnings history to qualify for DI benefits, which are more generous than SSI benefits. However, low-income disabled workers with very limited DI benefits can supplement low benefits with SSI to reach SSI benefit levels. Participation in the DI program for at least 24 months entitles beneficiaries to Medicare, and SSI recipients in most states automatically qualify for Medicaid (Gresenz et al., 1998). From the inception of the SSI/DI programs in the early 1970s, substance disorders were considered potentially disabling conditions. Initially, however, the number of beneficiaries in this impairment category was very small (Guydish, Ponath, Bostrom, Campbell, \& Barron, 2003). During the late 1980s and early 1990s, the number of SSI recipients with substance disorders began to grow rapidly - between 1989 and 1994, the number of SSI recipients in the substance disorder disability category increased from 16,100 to 101,685 (Barber, 1996). Figure 1 demonstrates the rapid growth and adjustment of the DA\&A caseload in the SSI program over time. In response to rapid growth in disability due to DA\&A, the federal government in 1994 imposed a three year time limit on receipt of disability benefits for those with disabling substance conditions (Guydish et al., 2003). 
In addition, SSA required DA\&A beneficiaries to obtain substance abuse treatment, to be enforced by referral and monitoring agencies.

Despite these changes in 1994, the number of DA\&A beneficiaries continued to rise during the 1990s, although as a group, they comprised less than 3 percent of the total SSI/DI adult population (Stapleton, Wittenburg, \& Tucker, 1998). The federal government became increasingly concerned that recipients were not engaging in treatment and returning to work, as intended by the program (Gresenz et al., 1998). Moreover, despite the requirement that SSI/DI payments to addicted persons be managed by individuals called representative payees, there was concern that disability payments were being used to purchase drugs. There was at that time and continues to be mixed empirical support for this claim (Catalano \& McConnell, 1999; Frisman \& Rosenheck, 1997; Rosen et al., 2006; Shaner et al., 1995; Swartz et al., 2003). Nevertheless, these perceptions contributed to a major policy change.

In March 1996, the US Congress passed P.L. 104-121, legislation terminating eligibility for SSI/DI programs on the basis of disabling drug addiction and/or alcoholism (DA\&A); new and pending applications for cases in which a SUD was material to the disability determination would no longer be considered (Davies et al., 2000). The legislation also mandated that existing DA\&A recipients be terminated from the program as of January 1, 1997 (Davies et al., 2000).

Individuals with SUDs were given the opportunity to be re-assessed for SSI/DI eligibility based on any co-occurring mental or physical disability. If re-assessed successfully, these recipients regained their cash benefits through the SSI/DI programs along with any related public health insurance benefits, but without required treatment activity or a representative payee (Watkins \& Podus, 2000). Of the 209,000 beneficiaries targeted by the January 1997 policy change, $80 \%$ were SSI beneficiaries and only $11 \%$ were DI beneficiaries who had never received SSI. $^{2}$ One year after the policy change, about 71,000 of the 209,000 targeted beneficiaries had regained SSI/DI eligibility (Stapleton et al., 1998). In other words, receipt of disability insurance among individuals disabled by SUDs fell by two thirds. As individuals with little work history who do not qualify for the more generous DI benefits, and given that the vast majority of DA\&A recipients received SSI payments, we expect that potential SSI recipients were those most vulnerable to any adverse consequences of the program change. Thus, for this reason and due to

\footnotetext{
${ }^{2}$ DI recipients whose benefits are below SSI levels can qualify for SSI to increase benefit levels. Thus, about 120,000 DA\&A beneficiaries qualified for both programs simultaneously (Campbell, Baumhol, and Hunt 2003).
} 
data limitations regarding DI receipt, we focus on SSI recipients in this analysis. Figure 1 shows administrative estimates of the overall SSI caseload, those collecting benefits for DA\&A, and for SSI recipients qualifying due to a mental health disorder (which would include the DA\&A population) over the 1990s and after 2000. The drop in SSI receipt from 1996 to 1997 is sudden, dramatic, and largely offset by later gains in the mental health caseload.

\section{B. Evidence on the Effects of Losing Disability Benefits on Individual Outcomes}

Individuals that received SSI/DI payments for DA\&A are an extremely disadvantaged group. DA\&A clients were mostly male (about 73 percent) and middle-aged (about 40 percent were between 40 and 49 years old) with high levels of psychiatric impairment, medical comorbidities, limited work experience, and low levels of education (Davies, Iams, \& Rupp, 2000; McKay, McLellan, Durell, Ruetsch, \& Alterman, 1998; Stapleton et al., 1998). Disability recipients targeted by the program changes had extensive criminal histories; a study of one large referral and monitoring agency suggests that about $84 \%$ of this population had been charged with a criminal offense, and nearly one third of males had a history of charges for a violent crime (Stapleton et al., 1998). As of 1995, about 53\% of substance abusers receiving SSI benefits were classified as alcohol dependent, 18\% were classified as drug dependent, and the remaining 29\% had both alcohol and drug dependence (Barber, 1996). The average monthly SSI payment to disabled substance abusers was $\$ 425$ in 1995, and 69\% of substance abusers receiving SSI in 1995 had no other source of income (Barber, 1996).

Given these characteristics, there has been concern that former DA\&A recipients may have faced significant barriers in entering the labor market and finding jobs after the policy change took place. Moreover, losing SSI/DI cash benefits, as well as losing the oversight of treatment and access to Medicare or Medicaid, may have adversely affected these individuals' mental and physical wellbeing, utilization of health services, and criminal involvement. The few studies available on this topic, however, offer mixed support for this idea.

Watkins, Podus, Lombardi, \& Burnam (2001), for example, follow 253 SSI beneficiaries in Los Angeles, interviewing them for the first time around the time the 1997 policy change went into effect and then again at 12 month, 18 month and 24 month follow-up interviews. Surprisingly, they find no evidence that the mental health status of respondents declined during this period, even though only 106 of the 253 respondents were still receiving SSI benefits at the 24 month follow-up interview. There also was no increase in emergency 
department visits and hospitalizations among respondents who lost SSI benefits (Watkins et al., 2001). The authors suggest that the lack of adverse consequences can be traced to other countybased programs such as General Assistance which may have replaced SSI benefits. Despite this type of speculation that state and local assistance programs may have provided resources for substance abusers who lost federal disability benefits, there is little if any systematic research on this topic.

Guydish et al. (2003) report similar null findings in a multi-site study of 1,670 individuals who at baseline were receiving SSI benefits for a disabling substance use condition. Most baseline interviews were conducted between November 1996 and March 1997. Respondents were then interviewed and administered the Addiction Severity Index (ASI) every six months over a two year follow-up period. Over time, they find either no change or improvement in ASI score, and no apparent association between ASI score and SSI receipt status. In the same multisite study, and the only evidence of labor market outcomes to date, Campbell et al. (2003) assessed employment and earnings among 661 study subjects who were not collecting SSI, welfare, or general assistance in the 24 months following the policy change. They found twofold to three-fold increases in employment rates six months after baseline, but earnings were very low. After 24 months, less than 25 percent of respondents earned more than $\$ 500$ per month (equivalent to the level of Substantial Gainful Activity, or the earnings level above which SSA considers individuals to be non-disabled) in six out of nine cities studied.

Finally, a recent study based on data from Chicago indicates that termination of SSI benefits may have led to reduced access to Medicaid. Hanrahan et al. (2004) used longitudinal data on 11,740 individuals who had been receiving SSI benefits for a substance disorder in Chicago in 1995, and showed that by 1998, almost half of these individuals had lost their Medicaid coverage (Hanrahan et al., 2004). The limited geography of this study makes it difficult to infer results in other parts of the country.

Because of the tremendous economic expansion of the late 1990s, our understanding of the effects of the policy change would be enhanced by comparing individuals targeted by the change to a control group of individuals unlikely to be affected by the termination of disability benefits. Furthermore, while results such as those found in Chicago regarding Medicaid declines are provocative, further information from a more geographically diverse sample would augment the evidence available regarding the elimination of cash benefits to individuals with disabling 
SUDs. Finally, with the passage of time, it is now possible to assess longer term effects of terminating disability benefits for SUDs, something that wasn't possible in prior studies.

The key question of interest to policymakers is the following: has the elimination of federal disability payments, as well as the health insurance and monitoring of treatment and finances that the disability programs previously provided, had long-term effects on economic self-sufficiency in the national population of individuals with disabling substance problems? Prior studies on this topic were based on data from geographically limited, narrowly defined populations and followed respondents for only about one to two years after the policy change took effect in 1997. Moreover, an important methodological limitation of prior studies is the lack of comparison groups; in these studies, outcomes are compared pre and post policy change in a group that was likely to be affected by the policy. These policies can affect not just those receiving benefits at the time of the legislation, but potential new applicants, as well as those individuals diverted from the welfare caseload, who might otherwise have qualified for SSI benefits. Even among those who maintained benefits because of co-occurring disorders, the new policy eliminated the requirement that individuals obtain treatment for their substance disorder, which might reduce the amount of treatment sought and obtained by those on SSI. Studies of individuals exiting SSI cannot capture any of these effects.

The present study uses repeated, nationally representative cross-sectional samples of individuals from the 1994-2002 NHSDA/NSDUH to examine the long-term, national effects of this important policy change. A second advantage of our paper is the utilization of a comparison group as well as several other methods to help control for or mitigate other, potential omitted variables and trends that may be related to the outcomes of interest.

\section{Data from National Household Surveys on Drug Use and Health}

We use pooled, annual, cross-sectional 1994-2002 data from the National Survey on Drug Use and Health (NSDUH), known as the National Household Survey on Drug Abuse (NHSDA) through 2001. The NHSDA/NSDUH is apt for this study because it is designed to produce substance use incidence and prevalence estimates for the general U.S. civilian, noninstitutionalized population aged 12 and older, including residents of non-institutional group quarters such as group homes, shelters, and rooming houses. The survey includes questions from the Diagnostic and Statistical Manual (DSM) of Mental Disorders that allow diagnostic criteria 
to be applied to identify symptoms of dependence or abuse of alcohol and various illegal and prescription drugs. Respondents are also asked about substance abuse treatment history, personal and family income sources and amounts, employment, health care access and coverage, and criminal record. The public use NHSDA/NSDUH does not include state identifiers, or any other potentially identifying information for respondents. Overall interview response rates are consistently close to 80 percent.

There were few important survey methodology changes prior to 1999 (Gfroerer et al., 2002). The 1994-1998 surveys used a multistage area probability sample design involving five selection stages: primary sampling units (PSUs; e.g. metropolitan areas, counties, groups of counties, and independent cities) selected to represent the total U.S. population, blocks or block groups, housing units or group quarters, age-group-smoking classes within sampled listing units, and eligible individuals within sampled age-group-smoking classes. Blacks, Hispanics and cigarette smokers were over-sampled, the latter to increase the precision of drug use estimates. Information was collected using confidential, anonymous, face-to-face interviews conducted in the household and self-administered answer sheets for sensitive topics such as drug use (Gfroerer et al., 2002). Annual samples for 1994 to 1998 averaged about 24,000 respondents.

Beginning in 1999, the national, stratified, multistage, area probability sampling design was changed to a larger, state-based design, which involved selecting independent, stratified, multistage, area probability samples from 50 states and the District of Columbia (Gfroerer et al., 2002). In the eight most populous states, over-sampling was used to select about 3,600 to 4,630 respondents from each of these states (CA, NY, TX, FL, PA, IL, MI and OH). In the remaining states and the District of Columbia, the target number of respondents was about 900 to 1,030. About a third of the initial sample was allocated to the 12 to 17,18 to 25 , and 26 or older age groups respectively so that separate state-level estimates could be generated for each of these age groups (Gfroerer et al., 2002).

The second change in the survey that took place in 1999 was a switch to computerassisted personal interviewing (CAPI) and audio computer-assisted self-interviewing. Computer-assisted interviewing yielded more internally consistent and complete data, and somewhat higher levels of reporting for some sensitive behaviors (Gfroerer et al., 2002).

As described above, implementation of the DDD method requires that we identify individuals who show evidence of having a recent, disabling substance problem. We consider 
two alternate ways of defining such a group. Our primary group of substance abusers - which we call the "broad" substance abuser group - includes individuals with at least one of the following: (1) heavy current use of alcohol and/or illicit drugs; or (2) 3 or more symptoms of an SUD for at least one single substance; or (3) receipt of any substance abuse treatment, including participation in a self-help group (e.g., Alcoholics Anonymous), in the past year. Heavy current use is defined as 3 or more alcohol binges (5+ drinks in one occasion) in the past 30 days; and/or 6 or more occasions of marijuana use in the past 12 months; and/or 3 or more occasions of other illicit drug use in the past 12 months. The substance disorder symptoms included in the NHSDA/NSDUH surveys are based on DSM criteria and are applied to alcohol, illegal drugs (including marijuana, hallucinogens, inhalants, cocaine/crack and heroin) and non-prescribed use of prescription drugs (including pain killers, tranquilizers, stimulants and sedatives). ${ }^{3}$

The advantage of using the broad substance abuser group is that it is inclusive enough to capture many different forms and stages of substance problems (e.g., alcohol abuse), but it is still stringent enough to be limited to individuals who are likely to have a recent disabling problem. Notably, this measure includes individuals with recent heavy use of substances, as well as those experiencing symptoms of disorder. Estimates generated from 2002 NSDUH data set indicate that the correlation coefficient between this heavy substance use measure and substance dependence is about 0.38 for women and about 0.41 for men, and these correlations are significant at the .001 level.

A possible disadvantage of the broad group, however, is that it may include some respondents who use substances heavily, but are not experiencing disabling problems associated with use. For this reason, we also consider an alternate, more stringently defined substance abuser group. Our "narrow" group is limited to individuals reporting either (1) 3 or more symptoms of substance disorder for at least one single substance; (2) receipt of any substance abuse treatment, including self-help groups, in the past year, or both (1) and (2). The narrow group includes only respondents who appear to meet DSM criteria for substance dependence. In our sample, as in reports on the pre-legislation DA\&A recipients, the majority qualify due to abuse of alcohol, as opposed to illicit drugs. When we categorize individuals into those suffering from at least 3 symptoms of an SUD or recipients of substance abuse treatment in the last year,

\footnotetext{
${ }^{3}$ The Appendix includes details regarding symptoms of substance abuse.
} 
$62 \%$ qualify due to alcohol only, versus $21 \%$ who qualify due to symptoms relating to an illicit drug only, and $18 \%$ relating to abuse or dependence of more than one substance. We note that our rate of symptoms relating to alcohol-only is higher than the rate of DA\&A recipients for alcohol only, but this could relate to the fact that individuals were more likely to report alcohol use and symptoms v. illicit drug abuse and symptoms in the NHSDA/NSDUH.

To maximize statistical power, our primary approach is to estimate models using a combined gender sample. To reflect the disadvantaged nature of the SSI eligible population, we limit the entire analysis sample to respondents with fewer than 16 years of education. We also confirmed that our results are robust to limiting the sample to respondents with 12 years of education or fewer, although limiting the sample in this way leads to a substantial loss of statistical precision. Together, including all surveys from the 1994B NHSDA through the 2002 NSDUH, 325,710 individuals were sampled, including 232,490 individuals aged 18-64. Of these respondents, 156,041 had less than 16 years of education and available information on all dependent variables and covariates.

We consider four types of outcomes: (1) receipt of public assistance; (2) labor market outcomes; (3) health insurance and health services utilization; and (4) arrests. NHSDA/NSDUH respondents were asked whether they had received any SSI payments in the last calendar year. To ensure that respondents understood that they were being questioned about payments from SSI versus another public support program, the interviewer specified that “...federal SSI checks are either automatically deposited in the bank or mailed to arrive on the first of every month. If mailed, they are sent in a blue envelope." Similarly, respondents were asked about welfare payments in the last calendar year, and respondents were instructed to exclude SSI. From these questions, we create binary indicators of SSI receipt and welfare receipt. Note that the NHSDA/NSDUH question regarding receipt of federal disability benefits specifically mentions SSI, and does not include payments from the DI program.

We also create binary variables indicating whether the respondent is 1) employed now; 2) in the labor force; and 3) currently disabled. ${ }^{4}$ To measure health insurance coverage, we create three variables that indicate whether the respondent is currently covered by: (1) any type of

\footnotetext{
${ }^{4}$ From 1994-1998, the employment and labor force variables are based on questions about the respondent's "present work status." In 1999-2002, these variables are based on a question regarding work status "in the past week."
} 
health insurance; (2) Medicaid; and (3) any type of private insurance. ${ }^{5}$ The interviewers specified that Medicaid is a public assistance program that pays for medical care, and also provided the name of the Medicaid program in the respondent's state. To measure utilization of health services, we create indicators of any visit to the emergency department in the past 12 months, and any inpatient hospital stay in the past 12 months. We also create two indicators specific to mental health services, given the likely high level of co-morbidity between mental and substance conditions in our sample. These indicators include: any psychiatric outpatient services in the past 12 months, and any psychiatric inpatient services in the past 12 months. The psychiatric inpatient question changed substantially after 1998, so we include only the first postperiod (1997-98) in these models. Finally, our measure of involvement with the criminal justice system is a binary indicator of whether or not the respondent reports being arrested and booked for any crime in the past 12 months. Arrest questions began in the 1995 survey; thus, we exclude 1994 in arrest models.

The public-use NSDUH/NHSDA does not include state identifiers, or time-invariant PSU identifiers that would allow identification of PSUs that remain in the sample over multiple years of the survey. As a result, using the public-use data, we cannot account for the possibility that fixed state-level characteristics and/or co-occurring state-level trends (e.g., trends in welfare and Medicaid) may confound an observed association between the SSI policy change and outcomes. Using the public use data, we also cannot control for autocorrelation within geographic units.

To address these limitations of the public-use data, we conducted a set of specification checks through a special, one-time arrangement with the Office of Applied Studies at SAMSHA. In these analyses, researchers at SAMSHA merged geographic identifiers into our analytic files and estimated alternative versions of short-run models (our model restricted to years 1994-1998) which included: state-level fixed effects; a set of time-varying state controls; and Huber/White standard errors adjusted for clustering on state. Appendix Table 1 describes our time-varying state covariates in detail. These covariates included: (1) whether the state had a major ADFC waiver approved; (2) whether Temporary Assistance to Needy Families (TANF) was officially implemented in the state; (3) the state unemployment rate; (4) the percent of all persons under age 65 in the state not covered by public or private insurance; (5) the percent of persons under

\footnotetext{
${ }^{5}$ The wording of the health insurance shifted slightly in the 1999 survey. In 1994 to 1998, respondents were asked whether they were covered by health insurance in the "current month." In later surveys, respondents were asked whether they had "current" health insurance.
} 
age 65 in the state covered by Medicaid; and (6) the state incarceration rate (number of prisoners sentenced to at least one year per 100,000 state residents).

\section{Empirical Approach}

\section{A. Identification Strategy}

As in any non-experimental setting, the central challenge in estimating the effects of this policy change on individual-level outcomes is determining whether or not an observed association represents a causal relationship. When analyzing the effects of the termination of disability benefits on economic and health care outcomes, results may arise from a causal relationship or from unmeasured factors affecting the outcome variable of interest at the same time as a major policy change. In this case, the association between the policy change and the outcome would not necessarily be causal.

In this paper, we combine several methods to attempt to circumvent this problem. Our general strategy is to compare changes in mean outcomes before and after the policy change for individuals most likely to have been targeted by the change and for otherwise similar individuals who were unlikely to have been affected. Our potentially targeted group consists of individuals who have both elevated probability of SSI use for a drug or alcohol-related disability based on their observed characteristics as well as recent heavy substance use and/or symptoms of substance dependence or receipt of substance abuse treatment. We compare changes pre- and post- policy change, among individuals who are and are not likely to have SUDs, interacting these characteristics (time period and treatment group) with an individual's predicted probability of SSI use. We predict SSI use based on coefficients from a model based on 1994-1996 data, before the legislation terminating SSI eligibility for DA\&A was passed. This difference-indifference-in-difference (DDD) approach mitigates the problem of unobserved heterogeneity, or the possibility that substance abusers likely to use SSI have fixed, unmeasured characteristics that differ from other individuals likely to use SSI (e.g., greater likelihood of co-morbid mental disorders) and affect the outcomes of interest.

Figure 2 demonstrates the intuition behind our strategy, although the details underlying the figure are explained in sections IV.B-IV.D. The figure shows the rate of SSI receipt and employment separately for our broad treatment group (likely substance abusers) and control 
group (non-substance abusers) among individuals with low and elevated predicted SSI receipt (in this figure, "elevated" indicates predicted SSI receipt $\geq .05$, or twice the population rate of SSI receipt), weighted by to balance the treatment and control groups. During the pre-period, within the elevated $\operatorname{Pr}(\mathrm{SSI})$ group, use of SSI is higher and employment is lower among the treatment groups. By 1997-98, the pattern was largely reversed.

We opt for this modified DDD approach to account for potentially confounding trends in outcomes between substance abusers and non-abusers that are not causally related to the policy change. Thus, by differencing out changes in outcomes between substance abusers and nonabusers, we address the possibility that an economy-wide trend that affected all substance abusers relative to non-abusers during this time period confounds the effects of the policy change (e.g. that substance abusers respond last to economic expansions). Similarly, by controlling for predicted SSI use, we net out trends affecting likely SSI users during the period surrounding the policy change. The basic econometric specification, ignoring covariates for the moment, is as follows.

$$
\begin{aligned}
& E\left[Y_{i t}\right]=\alpha+\beta_{1} S A_{i t}+\beta_{2} \operatorname{Pr}(S S I)_{i \operatorname{Pr} e-}+\beta_{3} S A_{i t} * \operatorname{Pr}(S S I)_{i \operatorname{Pr} e-}+\beta_{4} A_{f t e r 1996}+ \\
& \beta_{5} \text { After1998 }+\beta_{6} S A_{i t} * \text { After1996 } t+\beta_{7} S A_{i t} * \text { After1998 }+ \\
& \beta_{8} * \text { After } 1996_{t} * \operatorname{Pr}(S S I)_{i \operatorname{Pre}-}+\beta_{9} * \text { After } 1998_{t} * \operatorname{Pr}(S S I)_{i \operatorname{Pr} e-}+ \\
& \beta_{10} * S A_{i t} * \text { After } 1996_{t} * \operatorname{Pr}(S S I)_{t \text { Pre- }}+\beta_{11} * S A_{i t} * A_{f t e r 1998} * \operatorname{Pr}(S S I)_{i \operatorname{Pr} e-}
\end{aligned}
$$

In this equation, $\mathrm{SA}_{\mathrm{it}}=$ Substance Abuser (targeted group); $\operatorname{Pr}(\mathrm{SSI})_{\mathrm{iPre}}=$ predicted probability of using SSI during 1994-96 period; "After1996" = indicator for observations in 1997-2002; and “After1998" = indicator for observations in 1999-2002.

In this set up, $\mathrm{Y}_{\mathrm{it}}$ is an outcome variable for individual $\mathrm{i}$ in year $\mathrm{t}$. The key independent variables are the two triple interaction terms between substance abuser, the probability of SSI use based on pre-period program rules, and each of the two binary variables representing time periods after the federal government terminated DA\&A benefits ("After 1996" and "After 1998"). These coefficients represent the changes in outcomes pre- and post- policy change for substance abusers versus non-abusers allowing the effect to vary by individuals' probability of SSI use, based on pre-period relationships between observed characteristics and SSI receipt.

The "After 1996" and "After 1998" variables are determined only by time. The variables 
both take on a value of zero before the policy change (1993-1995 calendar years which correspond to the 1994-1996 survey years). After the policy change, the "After 1996" variable takes on a value of one for the rest of the study period (1996-2001 calendar years which correspond to the 1997-2002 survey years). Throughout the paper we will refer to survey years, rather than calendar years. The "After 1998" variable takes on a value of one for the 1999 to 2002 survey years. We view the policy change as occurring in calendar year 1996, since it was in March of this year that the legislation was enacted and individuals could no longer apply for SSI benefits if they had a substance-related disability. Note that this set-up allows the "After

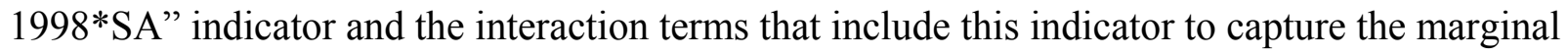
effects of the policy change in the long-run (1999-2002), relative to effects during 1997-98.

In this model, the DDD coefficients $\left(\beta_{10}\right.$ and $\left.\beta_{11}\right)$ are unbiased estimates of the policy effects in the short-run and the long-run effects relative to short-run effects. This interpretation will be correct as long as our identifying assumption, that no unmeasured event or policy change occurred at the same time as the SSI policy change that affected trends in outcomes over time differentially for substance abusers with a high probability of SSI use, holds. For example, a crucial policy change occurring during our study period was welfare reform, which was implemented in the mid- to late 1990s depending on the state. After passage of the 1996 Personal Responsibility and Work Opportunity Reconciliation Act (PRWORA), welfare benefits were subject to 60-month lifetime limits with shorter limits (12-36 months) for continuous benefit receipt in many states, and welfare recipients were subject to work requirements in exchange for cash payments. Welfare recipients who did not comply with requirements under PRWORA could have benefits sanctioned (either reduced or terminated). As 90 percent of welfare recipients are female, this would affect females disproportionately. Because our method differences out pre- and post- trends for individuals likely to use SSI benefits (presumably a group that also has an elevated rate of receiving welfare benefits), our approach may be contaminated by welfare reform only to the extent that its provisions differentially affected likely welfare users who were substance abusers. ${ }^{6}$ As described in the prior section, through an

\footnotetext{
${ }^{6}$ Some provisions of PRWORA could plausibly affect substance abusers more than others. Convicted felons can be denied welfare benefits under PRWORA, and the legislation allowed drug testing of welfare recipients so that states could deny benefits to individuals testing positive for illicit drug use. In practice no state has used suspicionless drug testing, but this could create an environment in which drug using women are less likely to apply for welfare benefits. Evidence on how PRWORA affects drug using women offers mixed results. Women reporting symptoms of substance dependence were more likely to be on welfare in the mid- to late 1990s (Danziger et al. 2000; Meara
} 
agreement with SAMSHA, as a specification check we estimated all of our short-run models with time-varying state characteristics that account for state-specific changes related to welfare reform, as well as changes in states' insurance coverage, unemployment, and incarceration rates, in order to address this potential problem. These models also included state-level fixed effects and Huber/White standard errors adjusted for clustering on state.

\section{B. Generating the Predicted Probability of SSI Use Based on 1994-96 Policies}

To create the probability of SSI use, we first estimate logit models to predict the probability of SSI use during the period before the legislative change (survey years 1994 through 1996) as a function of demographic characteristics.

$$
\operatorname{Pr}\left(\mathrm{SSI}_{\mathrm{it}}=1\right)=\mathrm{f}\left(\mathrm{X}_{\mathrm{it}}^{\prime} \beta\right)
$$

In this set-up, $\mathbf{X}_{\mathbf{i t}}$ is a vector of characteristics for individual $\mathbf{i}$, described below, and $\mathrm{f}($.$) is the$ logistic function, or $\mathrm{f}()=.\mathrm{e}^{\mathrm{x}} /\left(1+\mathrm{e}^{\mathrm{x}}\right)$. Using the coefficients from these models, we predicted the probability of SSI use for the entire sample of individuals (years 1994-2002). We then generate a continuous variable, $\operatorname{Pr}(S S I)_{i P r e-}$, indicating the respondent's predicted probability of SSI use during the pre-period. This variable and its interactions with other variables are then included in Equation 1, as described above. ${ }^{7}$

\section{Using Propensity Score Models to Balance Treatment and Control Groups}

As described above, the main methodological challenge to this study is forming an appropriate treatment and control group to address the potential omitted variable bias that could affect our interpretation of estimates as the effect of terminating disability benefits for substance abusers. We use propensity score-based weights to balance observed characteristics between substance abusers and others in our control group.

Using survey years 1994-1996, we estimate a logit model that predicts whether an

and Frank 2007; Montoya et al. 2003), but also more likely to be sanctioned following welfare reform (Meara and Frank 2007; Morgenstern 2003). Over a longer period, women with a history of illicit drug use were less likely to be on welfare (Pollack and Reuter 2006), but this disproportionate exit from welfare occurred after 2000, so it is likely to affect our long-run estimates only.

${ }^{7}$ In practice, $99 \%$ of pre-period respondents had a predicted probability of SSI use below .25 , and the propensity distribution most closely resembles actual SSI use for these respondents. Predicted SSI use was higher than actual SSI use among respondents in the top percentile of the $\operatorname{Pr}(\mathrm{SSI})$ distribution. To reduce the noise introduced by this error in predicting $\operatorname{Pr}(\mathrm{SSI})$ at the top of the distribution, we ranked respondents on predicted SSI use, divided the sample into 25 bins averaging 6,250 respondents each, and replaced the predicted $\operatorname{Pr}(\mathrm{SSI})$ with the average actual SSI use within that bin during the pre-period (survey years 1994-1996). Thus, our SSI propensities range from near zero to just under 25 . 
individual is a substance abuser as a function of observed characteristics.

$$
\operatorname{Pr}\left(\mathrm{SA}_{\mathrm{it}}=1\right)=\mathrm{f}\left(\mathrm{X}_{\mathrm{it}}^{\prime} \beta\right)
$$

This model has the same covariates as in (2) and again, $\mathrm{f}()=.\mathrm{e}^{\mathrm{x}} /\left(1+\mathrm{e}^{\mathrm{x}}\right)$. We use the estimated coefficients from (3) to generate the predicted probability of being a substance abuser, $p$, and we weight each observation in our sample by the probability of being in the opposite group. That is, individuals in the substance abuser group receive a weight of $(1-p)$, and individuals not in the substance abuser group receive a weight equal to $\mathrm{p}$, a propensity score weighting approach described in Li, Zaslavsky, and Landrum (2007). Like more commonly discussed inverse probability weighting techniques (Hirano \& Imbens, 2001), this balances observed characteristics across treatment and control groups. However, in this case, characteristics are balanced to resemble those among overlapping portions of the treatment and control distributions of observed characteristics. This adapted technique obtains average treatment effects, averaged over the distribution of covariates in the population where the treatment and control groups overlap as opposed to the entire population. This approach also minimizes the variance of our estimates, which can be excessively large in inverse probability weighting techniques when individuals have a very low propensity score. By construction, this propensity score weighting technique, used previously in the clinical and health services literature, forces the distribution of observed characteristics in the propensity model to be identical across the two groups (McWilliams et al. 2003). In the paper, all estimates presented weight each observation with the propensity-score-based weight multiplied by the sample weight provided in the NHSDA/NSDUH surveys, to make the data representative of the target population for the surveys. This modified weight balances the distribution of observed characteristics during the pre-period among substance abusers versus the comparison group.

In equations (2) and (3), we control for the following individual characteristics (X): gender, race/ethnicity (Black non-Latino, Latino, and Other non-Latino race versus white nonLatino), an indicator for whether the interview was conducted in Spanish, age categories (22-23, 24-25, 26-29, 30-34, 35-49, 50-65 versus 18-21), marital status (widowed, divorced, never married versus married), education ( 5 or fewer years, $6,7,8,9,10,11,13$, and 14-15, versus 12 years), veteran status, number of household inhabitants (dummies for 2 through $6+$ versus living alone), population density category (MSA $>1$ million, MSA $<1$ million versus not in an MSA), self-reported health status (poor, fair, good, very good versus excellent), ever used illicit drugs, 
used alcohol before age 15, used marijuana before age 17, and whether the respondent ever smoked daily. ${ }^{8}$ In the additional sensitivity analyses conducted by SAMSHA, we included state fixed effects in both models (Equations 2 and 3).

\section{Estimation}

Once we have obtained propensity-score based weights for each observation, we estimate models of our main labor market, health insurance, health care and arrest related outcomes. To aid interpretation of our coefficients of interest, we estimate these as linear probability models as in equation 4.

$$
\begin{aligned}
& Y_{i t}=\alpha+\beta_{1} S A_{i t}+\beta_{2} \operatorname{Pr}(S S I)_{i \operatorname{Pr} e-}+\beta_{3} S A_{i t} * \operatorname{Pr}(S S I)_{i \operatorname{Pr} e-}+\beta_{4} A_{\text {fter } 1996}+\beta_{5} \text { After } 1998_{t}+ \\
& \beta_{6} S A_{i t} * \text { After } 1996_{t}+\beta_{7} S A_{i t} * \text { After } 199{ }_{t}+\beta_{8} * \text { After } 1996_{t} * \operatorname{Pr}(S S I)_{i \operatorname{Pr} e-}+ \\
& \beta_{9} * \text { After } 1998 * \operatorname{Pr}(S S I)_{i \operatorname{Pr} e-}+\beta_{10} * S A_{i t} * \text { After } 1996 t_{t} * \operatorname{Pr}(S S I)_{i \operatorname{Pr} e^{-}}+ \\
& \beta_{11} * S A_{i t} * \text { After } 1998 * \operatorname{Pr}(S S I)_{i \operatorname{Pr} e-}+T_{t k}{ }^{\prime} \Gamma+\varepsilon_{i t}
\end{aligned}
$$

In addition to the substance abuse indicator, the predicted probability of SSI use, the "After 1996" and "After 1998" indicators, and interactions between these variables, we also include as controls a set of measures, $\mathbf{T}$, that vary across time $t$, and in some cases across group, $\mathrm{k}$. In the main analyses, these measures include the race/ethnicity-gender-specific national unemployment rate, the national rate of arrests per 100,000, and the national rate of incarceration per 100,000 . In the additional sensitivity analyses conducted through SAMSHA, these national time-varying variables are replaced by state fixed effects and state-level time varying measures of AFDC waiver approval, TANF implementation, state unemployment rates, state rates of insurance coverage, and state rates of incarceration. By controlling for these secular changes (main analyses) and state fixed and time-varying characteristics (sensitivity analyses), we rule out the possibility that measured effects resulted from policy changes related to welfare and public insurance programs, rising incarceration rates, or employment cycles that were unrelated to the termination of disability benefits for substance abusers.

Because of the binary nature of our outcome variables, we also estimate logit models of the above equation, and present these results in the Appendix for comparison. In the logit specification, one cannot interpret coefficients on the triple interaction terms as the DDD in the

\footnotetext{
${ }^{8}$ We tested whether our results were sensitive to the inclusion or exclusion of self-reported health status, given that it could plausibly be affected by the policy of interest, discontinuing disability benefits, but our results were unchanged, and precision was improved by the inclusion of health status in propensity models.
} 
probability of a binary outcome, as discussed in detail by (Ai and Norton 2003). Instead, we present results on the magnitude of effects based on predicted probabilities obtained from the logit coefficients in the models in three ways. In each case, we compare results for a 10 percentage point increase in $\operatorname{pr}(\mathrm{SSI})_{\mathrm{Pre}-\text { from }} .05$ to .15 , which allows us to make estimates within our range of data. First we present the DDD of effects in the early post-period, 1997-1998 versus 1994-1996 for substance abusers versus non- and for SSI propensities of .05 versus .15. Second we present the similar estimates of effects, but comparing the later post-period, 19992002 versus 1994-1996. Finally, we present the DDD estimate of effects in 1999-2002 versus 1997-98. For each of these, we bootstrap the standard errors of the DDD estimates with 100 replications.

In the OLS and logit models based on the public-use data, we adjusted for the stratified sampling design using Taylor Series Linearization methods and the information on Strata and Primary Sampling Units provided in the survey data. As discussed previously, because of the way the PSUs were reported in public use data, this method does not allow for correlation over time within sampling units (many of which were constant across some survey years). In the sensitivity analyses conducted through SAMSHA, we adjusted standard errors using Huber/White estimators, clustering at the level of state of residence.

\section{Results}

\section{A. Sample Characteristics}

Table 1 presents the propensity score-weighted characteristics of the broad treatment group, (heavy substance users, treatment in the past 12 months, or those with 3 or more symptoms of substance abuse or dependence) compared to the control group by time period. By construction, all of the observed demographic characteristics included in the propensity score model are perfectly balanced during the pre-period, so we show the outcome variables only (see Appendix Table 2 for the full set of covariates). It is notable that measures of public program use and labor market outcomes are relatively similar between substance abusers and others during the pre-period. SSI use is 4.1 percent among substance abusers compared with 3.2 percent in the comparison group. The percent employed is very similar among substance abusers (74.5 percent) and the comparison group (73.3 percent). Reported rates of disability are also similar, 3.9 v. 4.5 percent. Health care utilization is similar across groups with the exception of 
psychiatric services, though substance abuse treatment would be an example of a psychiatric service, so the substance use in the treatment group could affect that. Arrest rates are considerably higher among substance abusers, 6.1 percent versus the comparison group, 1.7 percent. This is not surprising given high arrest rates estimated among the DA\&A population. Given our inability to control for pre-period trends in arrest rates, results on arrests should be interpreted with caution. Otherwise, respondents in our broad treatment and comparison groups are highly likely to report exactly 12 years of education (45 percent) most are unmarried (51 percent) and the plurality (36 percent) of respondents are aged 35-49 (Appendix Table 2).

\section{B. Public Program Use}

Table 2 shows the estimated effects of the SSI policy change on public program use. As expected, SSI use drops disproportionately among individuals predicted to use SSI among both our treatment groups in 1997-98. Among the broad treatment group, SSI use drops by 81 percent in the short-run, an estimate that is similar to administrative estimates suggesting that at least two thirds of former DA\&A recipients had not re-qualified one year after the policy change took effect (Stapleton et al. 1998). Among the narrow treatment group, the estimated drop is close to 1, suggesting that for each percentage point increase in the probability of SSI use, individuals with symptoms of substance abuse are 1 percentage point less likely to use SSI after the policy change took effect. The drop in SSI receipt attenuates in the long run, however. Comparing SSI use in 1999-2002 relative to 1994-96, reductions in SSI use are no longer significant, and much smaller in magnitude compared with the 1997-98 effects. The logit models presented in the appendix document similar trends in the use of SSI following the policy change, and in fact, the implied magnitude of these changes closely mirror the drop in SSI receipt reported based on administrative data from SSA (Stapleton et al. 1998).

Table 2 confirms patterns documented elsewhere, that welfare use declined disproportionately among substance abusers, but only after 1998 (Pollack and Reuter 2006). In models predicting welfare use, the DDD estimates for 1997-98 were not statistically significant, but by 1999-2002 compared with the pre-period, welfare use was 31 percent lower in the broad treatment group, and 39 percent lower in the narrow treatment group relative to the comparison group.

\section{Labor Market Effects}

Table 3 presents estimates of the labor market effects of terminating disability insurance 
for substance abusers. The SSI policy change is associated with a substantial short-term increase in employment for individuals regardless of the treatment group used. For both the broad and narrow treatment groups, Table 3 suggests the policy change is associated with a one for one increase in employment as the probability of SSI use under pre-period rules rises. Among the broad treatment group, the employment effects persist, although they are smaller in magnitude by 1999-2002. The estimates suggest that employment was about 40 percent higher in the narrow treatment group in the long run compared to 1994-96. Consistent with these patterns, both broad and narrow treatment groups showed a disproportionate rise in labor force participation. The magnitude of these effects closely mirrors that of the employment effects, implying that the elevated employment represents individuals moving into the labor force rather than simply more successful job search during the booming economy of the late 1990s. Another interesting and intuitive result in Table 3 is that the employment effects seem to be larger for full-time work compared with part-time work. Logit models confirm that employment, in particular full-time employment, and labor force participation rose substantially and disproportionately among likely SSI users. Estimates of these effects are significant at conventional levels based on the bootstrapped variance estimates associated with the logit models.

The large magnitude and persistence of the employment effects among the broad treatment group are somewhat surprising given more moderate effects on SSI receipt in the long run. As discussed before, the policy change affected both SSI and DI programs, and we are unable to directly observe DI receipt. It is possible that the employment effects reflect changes in the population of substance abusers likely to use DI (which one would expect to be correlated with the propensity to use SSI). This could potentially explain the large employment effects in the face of a more moderate effect on SSI. An alternative explanation is that other time varying factors disproportionately affected the target group, high propensity SSI users who also report heavy substance use. Although multiple factors could create the pattern of work and SSI receipt we observe, it seems likely that individuals were influenced by the termination of disability, since these policies signaled a change in attitude towards individuals with SUDs. D. Specification check: state-level factors

Our main results, demonstrating less reliance on public programs in the short-run and increased employment in the face of the termination of SSI benefits, are based on specifications 
that do not have controls for underlying trends in a respondent's state. Table 4 shows the results of a specification check using restricted data with state identifiers (analyzed by SAMHSA) from 1994-98. In these models, we control for fixed state effects and time varying state trends including welfare waivers, TANF implementation, incarceration rates, unemployment rates, rates of uninsurance, and state Medicaid participation rates. The pattern in Table 4 mirrors what we found in our main analyses in Tables 2 and 3. SSI use falls substantially, and both labor force participation and employment rise in the first two years following the policy change. We take this as evidence that our results do not reflect state-specific trends that disproportionately affect likely users of SSI with SUDs.

\section{E. Health Insurance}

One aspect of welfare reform and reforms to SSI/DI that has received much attention is the potential loss of health insurance benefits as individuals exit public programs for work. This could happen explicitly, as in the case of terminating SSI benefits and linked eligibility for Medicaid, or indirectly, as a result of exceeding income limits for Medicaid eligibility once employed, but with no alternative source of coverage through an employer or privately. Indeed, in the late 1990s, there is evidence that low-income female caregivers who reduced rates of drug and alcohol use simultaneously reduced use of public programs, increased rates of employment, and were more likely than other low-income women to become uninsured (Meara and Greenfield 2008). The rate of health insurance, and the form of insurance among those covered did not change disproportionately for individuals who were heavy substance users or those with symptoms of dependence. Medicaid coverage did not fall significantly for this group, although the sign of the effect was negative and the magnitude was large. In the longer run, Medicaid receipt differed little for likely substance abusers with a high propensity to use SSI compared with others, and there were no long-run changes in the share of individuals reporting any health insurance coverage. Logit models on health insurance yield similar results, suggesting that among substance abusers likely to use SSI, health insurance status did not change significantly.

\section{F. Other Outcomes - Health care utilization and Arrests}

Because we documented no disproportionate change in health insurance status or source of coverage, it is unclear whether one should expect large changes in health care utilization. In Table 6, the likelihood of reporting an ER visit, a hospital or psychiatric admission all increased in 1997-2002, but these differences were not statistically significant in the linear probability 
models. The logit models (Appendix Table 5) suggest that hospitalizations increased among the broad treatment group. On balance, given little power to detect differences in these relatively rare events, we have no evidence to suggest systematic change in utilization after termination of SSI benefits for substance abuse.

The final two columns in Table 6 display results from models of arrests. This analysis must be interpreted with caution because the assumption that arrests should move together in the treatment and control groups is strong given the difference in levels of arrest rates before the policy change between these groups. Because we lack arrest data before 1995, we were unable to compare trends in arrests during the pre-period. With this caveat in mind, however, the results suggest a disproportionate rise in arrests in both treatment groups in the longer term, with the effect being most immediate and largest among the narrow treatment group. These arrest effects are statistically significant only in the logit-based long run estimates presented in Appendix Table 5. We view these results as suggestive evidence that termination of SSI benefits for may increase criminal activity among individuals with symptoms of substance abuse or dependence.

\section{G. Compositional Changes in the Sample}

One threat to our empirical approach is the fact that we do not follow the same individuals over time. Thus, if the termination of SSI benefits either increased or decreased substance abuse in the population, our results could be driven by compositional changes in the treatment and control groups rather than by changes in the outcomes of interest. We tested for changes in the composition of our sample by estimating models where presence in a treatment group was the dependent variable. The explanatory variables of interest were the same as in equation 3. We also tested for changes in household composition (the likelihood that individuals live alone, for example) since household composition might be another channel through which the policy could change other outcomes. In all cases, there were no significant changes in the composition of our sample compared with the baseline period of 1994-96 (Results available upon request). This evidence offers further support for our research design despite the limitations posed by the lack of longitudinal data.

\section{Conclusions}

In the mid-1990s, multiple reforms aimed to increase self-sufficiency among potential recipients of public income support. In this spirit, the 1997 termination of federal disability 
benefits for individuals with disabling substance disorders was no different in that it eliminated potential disincentives to work related to the availability of disability benefits. There has been concern, however, that these benefits are the only legal means by which addicted persons can obtain income to satisfy their basic needs and access health and treatment services. Recent studies have failed to uncover changes in substance abusers' outcomes in response to the policy shift, but these studies primarily analyze small, geographically constrained samples, and available evidence to date lacks a control group against which to compare outcomes for individuals affected by the termination of benefits. Furthermore, former literature in this area offers limited evidence on variables measuring self-sufficiency such as labor market participation and employment, and no existing study attempted to assess effects of the policy change beyond 24 months. In this paper, we examined trends in labor market outcomes, public program participation, health care access and utilization, and self-reported arrests among substance dependent individuals using a much larger national sample over a period that began three years before the policy change and extends until 2001 (survey year 2002), allowing for the estimation of both short-run and longer term effects.

Our findings confirm earlier work showing few measurable negative consequences of the policy change, though with one possible, and potentially important exception. The use of SSI fell disproportionately for the targeted groups, and there appears to have been no replacement of SSI benefits with welfare benefits, which is not surprising given coincident reforms to welfare. Labor force participation and employment rose substantially faster for our treatment groups compared with others. The persistent rise in employment among heavy substance users was fueled by increases in full-time work. Among individuals with three or more symptoms of substance abuse or dependence, the labor market effects differed. Individuals with symptoms of abuse or dependence increased employment in 1996 and 1997, but they were less likely to hold onto employment gains. Health insurance status and source of coverage did not change measurably. Consistent with this, the analyses of health care utilization yield few, if any, systematic effects related to the policy change, although the pattern of results suggest that psychiatric outpatient visits fell following the change while ER visits and hospital admissions rose. Most disturbingly, arrests rose disproportionately among likely SSI users with symptoms of drug dependence.

During the 1990s, the labor market reached unprecedented levels of employment, 
especially among those with relatively few skills or labor market experience. In such an era, we document that employment rose, and remained elevated among a group of individuals likely to use SSI and with moderate to heavy substance use. Among our narrow treatment group, individuals with symptoms of dependence or in substance abuse treatment, there was a relatively short-lived employment response. That is, employment increased in the months following the policy change, but by 1999-2002, employment fell for these individuals. This mirrors the finding that most employment among former DA\&A recipients failed to meet levels of Substantial Gainful Activity established for federal disability programs (Campbell et al. 2003).

Our results suggest that disability programs have provided income support to individuals unable to maintain attachment to the labor force even during a period of strong economic conditions. Fortunately, the expected disastrous consequences of lost of health insurance, and heavier utilization of inpatient or emergency medical services did not occur or were too small to observe. Of course, we were unable to assess other important indicators of well-being, like income, changes in drug use, changes in the rate or severity of mental health disorders, or changes in eviction and/or homelessness, among this population. Aside from productivity losses, the largest cost of substance abuse stems from crime. We find that arrests increased following termination of disability for individuals with heavy substance use or symptoms of SUDs.

Because many individuals with a history of substance use did increase self-sufficiency through increased employment and a reduction in the use of public programs, the results shown here suggest, on balance, that the individuals targeted by the termination of SSI/DI benefits for substance abuse, had relatively few disasters. The short term responses, however, suggest an interesting set of new questions. In particular, with these data we do not know how individuals entered the labor market, and what services, if any, aided them in their search for employment. Additional information on the nature of jobs held by individuals during this unique period, and the circumstances under which individuals left, are crucial for understanding the complete ramifications of policy changes aiming to increase self-sufficiency entirely through incentives.

Questions regarding the employment histories of individuals with SUDs are increasing in importance as the recent reauthorization of TANF has further limited states' ability to address the needs of welfare recipients with substance abuse issues. States are no longer at liberty to exempt women from work requirements while they obtain treatment for substance use or mental health disorders. Furthermore, the new regulations require more hours of work, and higher 
participation requirements. It is difficult to forecast the effects of these limitations, but they signal a new era under which vulnerable, low-skilled individuals with SUDs increasingly have fewer sources of support as they seek the very self-sufficiency that reforms of the mid-1990s aimed to achieve.

\section{References}

Ai, Chunrong. and Edward C. Norton. 2003. Economic Letters. "Interaction Terms in Logit and Probit Models." 80(1), 123-129.

Barber, Sherry L. 1996. "Supplemental Security Income Recipients for Whom the Alcoholism and Drug Addiction Provisions Apply (DA\&A Recipients)." Washington DC: Office of Program Benefits Policy, Social Security Administration.

Campbell, Kevin., Jim Baumohl, and Sharon R. Hunt. 2003) "The Bottom Line: Employment and Barriers to Work Among Former SSI DA\&A Beneficiaries." Contemporary Drug Problems, 30(Spring-Summer): 195-240.

Catalano, Ralph, and William McConnell. 1999. "Psychiatric Emergencies: The Check Effect Revisited." Journal of Health and Social Behavior, 40(March), 79-86.

Cohen, William S.. 1994. Tax Dollars Aiding and Abetting Addiction: Social Security Disability and SSI Cash Benefits to Drug Addicts and Alcoholics. Washington, D.C.: U.S. Government Printing Office.

Danziger, Sandra, Mary Corcoran, \& Danziger, Sheldon. 2000. "Barriers to the Employment of Welfare Recipients.” In R. Cherry \& W. Rodgers (Eds.), Prosperity for All? The Economic Boom and African Americans. New York: Russell Sage Foundation. 245-278. Davies, Paul, Howard Iams, and Kalman Rupp. 2000. "The Effect of Welfare Reform on SSA's Disability Programs: Design of Policy Evaluation and Early Evidence.” Social Security Bulletin, 63(1), 3-11.

Frisman, Linda and Robert A. Rosenheck. 1997. "The Relationship of Public Support Payments to Substance Abuse Among Homeless Veterns with Mental Illness." Psychiatric Services, 48(6), 792-795.

Gfroerer, J., Eyerman, J., and Chromy, J., Eds. (2002). Redesigning an ongoing national household survey: Methodological issues. DHHS Publication No. SMA 03-3768. 
Rockville, MD: Substance Abuse and Mental Health Services Administration, Office of Applied Studies.

Gresenz, Carole, Katherine E. Watkins, and Deborah Podus. 1998. "Supplemental Security Income (SSI), Disability Insurance (DI), and Substance Abusers." Community Mental Health Journal, 34(4), 337-350.

Guydish, Joseph R.. et al. 2003. Effects of losing SSI benefits on standard drug and alcohol outcome measures. Contemporary Drug Problems, 30(Spring/Summer), 169-193.

Hanrahan, Patricia., Daniel J. Luchins, Lea Cloninger, and James Swartz. 2004. Medicaid Eligibility of Former Supplemental Security Income Recipients With Drug Abuse or Alcoholism, American Journal of Public Health, (941), 46-47

Hirano, Keisuke, Imbens, Guido W. and Ridder, Geert, 2000, "Efficient Estimation of Average Treatment Effects Using the Estimated Propensity Score" (2000-03-01). Cambridge, MA: NBER Working Paper No. T0251.

Li, Fan, Alan M. Zaslavsky, Mary Beth Landrum, 2007, "Propensity Score Analysis with Hierarchical Data," Boston, MA, Manuscript.

McClellan, A.Thomas et al.. 2000. "Drug Dependence, a Chronic Medical Illness: Implications for Treatment, Insurance, and Outcomes Evaluation.” Journal of the American Medical Association, 284(13), 1689-1695.

McKay, James R., et al. 1998. "Characteristics of Recipients of Supplemental Security Income (SSI) Benefits for Drug Addicts and Alcoholics.” The Journal of Nervous and Mental Disease, 186(5), 290-298.

McWilliams, J. Michael et al. 2004. "Health Insurance Coverage and Mortality among Nearelderly Adults." Health Affairs, 23(4), 223-233.

Meara, Ellen. 2006. "Welfare Reform, Employment, and Drug and Alcohol Use among LowIncome Women." Harvard Review of Psychiatry 14(4): 223-232.

Meara, Ellen and Richard G. Frank. 2006. "Welfare Reform, Work Requirements, and Employment Barriers." NBER Working Paper Series. Cambridge, MA.

Meara, Ellen and Shelly F. Greenfield. 2008 "The Relationship Between Substance Use Patterns and Economic and Health Outcomes Among Low-Income Caregivers and Children." Psychiatric Services, 59(9): 974-981.

Metsch, Lisa. R. and Harold. A. Pollack. 2005. "Welfare Reform and Substance Abuse." The 
Milbank Quarterly 83(1): 65-99.

Montoya, Isaac. D. et al. 2002. "Mental Health, Drug Use, and the Transition from Welfare to Work." Journal of Behavioral health Services and Research, 29(2), 144-156.

Morgenstern, Jon et al. 2001. "Specialized Screening Approaches can Substantially Increase the Identification of Substance Abuse Problems among Welfare Recipients." Available at: http:/humanservices.ucdavis.edu/resource/uploadfiles/Specialized\%20Screening.pdf

NHSDA. 2002. The NHSDA report: Serious mental illness among adults. Retrieved 6 December 2002, from http://www.samhsa.gov/oas/2k2/SMI/SMI.cfm

Phillips, David, Nichaolas Christenfeld and Natalie Ryan. 1999. "An increase in the number of deaths in the United States in the first week of the month: an association with substance abuse and other causes of death." New England Journal of Medicine, 341, 93-98.

Pollack, Harold. A. et al. 2002. "Drug Testing Welfare Recipients--False Positives, False Negatives, Unanticipated Opportunities." Women's Health Issues 12(1): 23-31.

Pollack, Harold A., and Peter Reuter. 2006. "Welfare Receipt and Substance-Abuse Treatment Among Low-Income Mothers: the Impact of Welfare Reform." American Journal of Public Health, 96(11), 2024-2031.

Rosen, Marc, Thomas J. McMahon, HaiQun Lin, and Robert A. Rosenheck. 2006. "Effect of Social Security Payments on Substance Abuse in a Homeless Mentally Ill Cohort". Health Services Research, 41(1), 173-191.

Rosenheck, Robert, Linda Frisman., and Gallup. 1995. "Effectiveness and Cost of Specific Treatment Elements in a Program for Homeless Mentally Ill Veterens." Psychiatric Services, 46(1131-1139).

Rossi, P. 1989. Down and Out in America: The Causes of Homelessness. Chicago: University if Chicago Press.

Schmidt Laura A, and Dennis McCarty.2000. "Welfare Reform and the Changing landscape of Substance Abuse Services for Low-income Women.” Alcoholism: Clinical and Experimental Research. ;24:1298-311.

Shaner, Andrew., et al. 1995. "Disability Income, Cocaine Use, and Repeated Hospitalization Among Schizophrenic Cocaine Abusers." New England Journal of Medicine, 333(12), 777-783.

Sosin, Michael and Susan Grossman. 1991. "The mental health system and the etiology of 
homelessness: a comparison study." Journal of Community Psychology, 19, 337-350.

Stapleton, David C., David Wittenburg, and Adam Tucker. 1998. Policy Evaluation of the Effect of Legislation Prohibiting the Payment of Disability Benefits to Individuals Whose Disability is Based on Drug Addiction and Alcoholism. Interim Report Submitted by the Lewin Group, Inc. to the Social Security Administration, Contract No. 660-96-27331.

Swartz, James., Hsieh, C.M., and Jim Baumohl, 2003. "Disability payments, drug use and representative payees: an analysis of the relationships." Addiction, 98, 965-975.

Watkins, Katherine and Deborah Podus. 2000. "The Impact of Terminating Disability Benefits for Substance Abusers on Substance Use and Treatment Participation." Psychiatric Services, 51(11), 1371-1381.

Watkins, Katherine., Deborah Podus, Elizabeth Lombardi, and Audrey Burnham. 2001. "Changes in Mental Health and Service Use After Termination of SSI Benefits." Psychiatric Services, 52(9), 1210-1215.

White, Halbert. 1980. "A Heteroskedasticity-consistent Covariance Matrix Estimator and a Direct Test for Heteroskedasticity." Econometrica, 48, 817-83. 


\begin{tabular}{|c|c|c|c|c|c|c|c|}
\hline & & Pre-Perio & 994-1996 & 199 & 1998 & 1999 & 002 \\
\hline & & $\begin{array}{l}\text { Substance } \\
\text { Abuser }\end{array}$ & $\begin{array}{c}\text { Not a } \\
\text { substance } \\
\text { abuser }\end{array}$ & $\begin{array}{l}\text { Substance } \\
\text { Abuser }\end{array}$ & $\begin{array}{c}\text { Not a } \\
\text { substance } \\
\text { abuser }\end{array}$ & $\begin{array}{c}\text { Substance } \\
\text { Abuser }\end{array}$ & $\begin{array}{c}\text { Not a } \\
\text { substance } \\
\text { abuser }\end{array}$ \\
\hline Depende & variables: & $\mathrm{n}=5,756$ & $\mathrm{n}=21,950$ & $\mathrm{n}=4,517$ & $\mathrm{n}=20,140$ & $\mathrm{n}=20,123$ & $\mathrm{n}=83,555$ \\
\hline Labor ma & ret \& program participation: & & & & & & \\
\hline & SSI & 0.041 & 0.032 & 0.025 & 0.039 & 0.042 & 0.035 \\
\hline & Welfare & 0.050 & 0.051 & 0.045 & 0.034 & 0.030 & 0.028 \\
\hline & Employed & 0.745 & 0.733 & 0.743 & 0.757 & 0.762 & 0.796 \\
\hline & Full-time & 0.596 & 0.596 & 0.617 & 0.633 & 0.588 & 0.643 \\
\hline & Part-time & 0.145 & 0.128 & 0.118 & 0.117 & 0.131 & 0.115 \\
\hline & In Labor Force & 0.816 & 0.785 & 0.813 & 0.806 & 0.815 & 0.830 \\
\hline & Disabled & 0.039 & 0.044 & 0.034 & 0.051 & 0.050 & 0.047 \\
\hline Health In & Irance: & & & & & & \\
\hline & Any health insurance & 0.739 & 0.766 & 0.745 & 0.788 & 0.752 & 0.795 \\
\hline & Private health insurance & 0.641 & 0.655 & 0.652 & 0.693 & 0.638 & 0.691 \\
\hline & Medicaid & 0.075 & 0.083 & 0.070 & 0.071 & 0.087 & 0.076 \\
\hline Health ca & utilization: & & & & & & \\
\hline & ER visit & 0.211 & 0.200 & 0.225 & 0.198 & 0.351 & 0.299 \\
\hline & Inpatient stay & 0.079 & 0.091 & 0.086 & 0.086 & 0.105 & 0.088 \\
\hline & Inpatient psychiatric stay & 0.010 & 0.005 & 0.013 & 0.005 & -- & -- \\
\hline & Psychiatric outpatient services & 0.069 & 0.052 & 0.080 & 0.051 & 0.116 & 0.059 \\
\hline Arrested: & past year & 0.061 & 0.017 & 0.069 & 0.016 & 0.128 & 0.045 \\
\hline
\end{tabular}

${ }^{\mathrm{A}}$ Sample limited to respondents with $<16$ years of education weighted by both sampling and propensity-score based weights. ${ }^{\mathrm{B}}$ Substance Abuser $=$ respondents reporting moderate/heavy substance use, and/or 3+ symptoms of disorder, and/or substance treatment (including self-help groups) in last year. See text for details. ${ }^{C}$ Information on mental health inpatient stays is not comparable during 1999-2002 period. ${ }^{\mathrm{D}}$ Employment is based on "present work status." E Health insurance refers to coverage at survey (or in survey month). 


\begin{tabular}{|c|c|c|c|c|}
\hline \multicolumn{5}{|c|}{ Table 2: Public Program Participation } \\
\hline & \multicolumn{2}{|c|}{ SSI } & \multicolumn{2}{|c|}{ Welfare } \\
\hline & Broad & Narrow & Broad & Narrow \\
\hline $\operatorname{Pr}(\mathrm{SSI})$ & $1.27 * *$ & $1.21 * * *$ & $.314^{* * *}$ & $.329 * * *$ \\
\hline$(1994-1996)$ & $(.136)$ & $(.151)$ & $(.066)$ & $(.077)$ \\
\hline \multirow[t]{2}{*}{ After 1996} & $.016^{*}$ & .021 & $-.014 * *$ & $-.018^{* *}$ \\
\hline & $(.009)$ & $(.015)$ & $(.006)$ & $(.009)$ \\
\hline \multirow[t]{2}{*}{ After 1998} & $.022 * * *$ & $.027 * *$ & .009 & .008 \\
\hline & $(.007)$ & $(.011)$ & $(.006)$ & $(.009)$ \\
\hline $\operatorname{Pr}(\mathrm{SSI}) *$ & .200 & .201 & $-.194 * *$ & $-.197 * *$ \\
\hline After 1996 & $(.221)$ & $(.276)$ & $(.082)$ & $(.100)$ \\
\hline $\operatorname{Pr}(\mathrm{SSI}) *$ & $-.435 * *$ & $-.440^{*}$ & .084 & .076 \\
\hline After 1998 & $(.202)$ & $(.247)$ & $(.058)$ & $(.072)$ \\
\hline \multirow[t]{2}{*}{ Treatment Group } & -.004 & -.007 & -.008 & -.003 \\
\hline & $(.007)$ & $(.013)$ & $(.005)$ & $(.007)$ \\
\hline \multirow[t]{2}{*}{ Tx*After 1996} & .004 & .007 & .013 & .015 \\
\hline & $(.009)$ & $(.017)$ & $(.008)$ & $(.012)$ \\
\hline \multirow[t]{2}{*}{ Tx*After 1998} & .003 & .010 & -.0003 & -.0006 \\
\hline & $(.007)$ & $(.012)$ & $(.007)$ & $(.010)$ \\
\hline \multirow{2}{*}{$\operatorname{Pr}(\mathrm{SSI}) * \mathrm{Tx}$} & .352 & $.753 *$ & .239 & .159 \\
\hline & $(.318)$ & $(.430)$ & (.159) & $(.179)$ \\
\hline $\operatorname{Pr}(\mathrm{SSI}) * \mathrm{Tx} *$ After & $-.806^{* *}$ & $-.995 * *$ & -.017 & .047 \\
\hline 1996 & $(.349)$ & $(.507)$ & $(.220)$ & $(.272)$ \\
\hline $\operatorname{Pr}(\mathrm{SSI}) * \mathrm{Tx} *$ After & $.479^{*}$ & .299 & $-.309 * *$ & $-.393^{*}$ \\
\hline 1998 & $(.280)$ & $(.381)$ & $(.155)$ & $(.229)$ \\
\hline \multicolumn{5}{|c|}{$\begin{array}{l}\text { NOTES: Based on linear probability models that account for the complex } \\
\text { survey sample design. Propensity score-based weights are used to match } \\
\text { observed characteristics between treatment and control groups. Robust, } \\
\text { Huber-White corrected SEs shown in ( ) correct for correlation within } \\
\text { sampling units. } *=\text { p-value }<=.10, * *<=.05, * * *<=.01 \text {. Models also include } \\
\text { controls for race-gender specific national unemployment rate, national } \\
\text { arrest rate per } 100,000 \text { and national incarceration rate per } 100,000 \\
\text { (coefficients not shown). Analyses are based on a sample size of } 156,041 \text {. }\end{array}$} \\
\hline
\end{tabular}




\begin{tabular}{|c|c|c|c|c|c|c|c|c|c|c|}
\hline \multirow[t]{2}{*}{ Outcome: } & \multicolumn{2}{|c|}{ Employed } & \multicolumn{2}{|c|}{ Full-time } & \multicolumn{2}{|c|}{ Part-time } & \multicolumn{2}{|c|}{ Disabled } & \multicolumn{2}{|c|}{ In labor force } \\
\hline & Broad & Narrow & Broad & Narrow & Broad & Narrow & Broad & Narrow & Broad & Narrow \\
\hline $\operatorname{Pr}(\mathrm{SSI})$ & $-1.93 * * *$ & $-1.81 * * *$ & $-1.65 * * *$ & $-1.46 * * *$ & $-.316 * * *$ & $-.373 * * *$ & $1.71 * * *$ & $1.57 * * *$ & $-1.82 * * *$ & $-1.63 * * *$ \\
\hline$(1994-1996)$ & $(.153)$ & $(.169)$ & $(.160)$ & $(.176)$ & $(.072)$ & $(.075)$ & $(.129)$ & $(.133)$ & $(.155)$ & $(.169)$ \\
\hline \multirow[t]{2}{*}{ After 1996} & $.030 *$ & $.043 *$ & .031 & $.050 *$ & -.005 & -.005 & .0001 & .0004 & .017 & .019 \\
\hline & $(.018)$ & $(.025)$ & $(.021)$ & $(.027)$ & $(.013)$ & $(.014)$ & $(.008)$ & $(.011)$ & $(.018)$ & $(.024)$ \\
\hline \multirow[t]{2}{*}{ After 1998} & .020 & .018 & .007 & .006 & $-.023 *$ & -.016 & $.019 * *$ & $.029 * *$ & .009 & -.005 \\
\hline & $(.015)$ & (.019) & (.019) & $(.025)$ & $(.010)$ & $(.015)$ & $(.008)$ & $(.012)$ & $(.013)$ & $(.017)$ \\
\hline $\operatorname{Pr}(\mathrm{SSI}) *$ & $-.450 * *$ & -.448 & $-.371 *$ & -.337 & -.050 & -.111 & $.610 * * *$ & $.707 * * *$ & $-.423 *$ & $-.518 *$ \\
\hline After 1996 & (.219) & $(.287)$ & $(.226)$ & $(.282)$ & $(.119)$ & $(.111)$ & $(.213)$ & $(.278)$ & $(.226)$ & $(.290)$ \\
\hline $\operatorname{Pr}(\mathrm{SSI}) *$ & $.537 * * *$ & $.715 * * *$ & $.575 * * *$ & $.653 * * *$ & -.079 & .061 & $-.446 * *$ & $-.605 * *$ & $.478 * *$ & $.632 * *$ \\
\hline After 1998 & $(.198)$ & $(.250)$ & $(.201)$ & $(.249)$ & $(.099)$ & $(.101)$ & $(.208)$ & $(.254)$ & $(.211)$ & $(.263)$ \\
\hline \multirow[t]{2}{*}{ Treatment Group } & $.038 * * *$ & .012 & .016 & -.012 & $.025 * *$ & $.025^{*}$ & $-.011^{*}$ & -.010 & $.051 * * *$ & .024 \\
\hline & $(.013)$ & $(.021)$ & $(.015)$ & $(.022)$ & $(.011)$ & $(.014)$ & $(.006)$ & $(.008)$ & $(.013)$ & $(.020)$ \\
\hline \multirow[t]{2}{*}{ Tx*After 1996} & $-.066 * * *$ & $-.077 * * *$ & $-.048^{*}$ & $-.061 *$ & -.021 & -.023 & .008 & .005 & $-.065 * * *$ & $-.086 * * *$ \\
\hline & $(.022)$ & $(.031)$ & $(.025)$ & $(.036)$ & $(.014)$ & $(.022)$ & $(.009)$ & $(.013)$ & $(.020)$ & $(.029)$ \\
\hline \multirow[t]{2}{*}{ Tx*After 1998} & -.007 & .024 & -.023 & .019 & .011 & .002 & .008 & .020 & -.005 & .038 \\
\hline & $(.020)$ & $(.026)$ & $(.023)$ & $(.030)$ & $(.011)$ & $(.017)$ & (.009) & $(.013)$ & $(.017)$ & $(.025)$ \\
\hline \multirow[t]{2}{*}{$\operatorname{Pr}(\mathrm{SSI}) * \mathrm{Tx}$} & $-.749 * * *$ & $-.816^{* *}$ & -.360 & -.350 & $-.343 * *$ & $-.413 * * *$ & .152 & .241 & $-.551^{*}$ & $-.776^{*}$ \\
\hline & $(.289)$ & $(.403)$ & (.299) & $(.404)$ & $(.151)$ & $(.149)$ & $(.325)$ & $(.392)$ & $(.307)$ & $(.408)$ \\
\hline $\operatorname{Pr}(\mathrm{SSI}) *$ & $1.14 * * *$ & $1.16^{*}$ & $.835^{*}$ & .772 & .253 & .373 & -.610 & -.631 & $1.21 * * *$ & $1.75^{* * *}$ \\
\hline Tx*After 1996 & $(.443)$ & $(.619)$ & $(.465)$ & $(.620)$ & $(.201)$ & $(.241)$ & $(.424)$ & $(.606)$ & $(.436)$ & (.614) \\
\hline $\operatorname{Pr}(\mathrm{SSI}) *$ & -.202 & -.695 & -.300 & -.762 & .121 & .074 & .206 & .356 & -.368 & $-1.13^{* *}$ \\
\hline Tx*After 1998 & $(.397)$ & $(.505)$ & $(.408)$ & $(.500)$ & $(.174)$ & $(.237)$ & $(.384)$ & $(.494)$ & $(.392)$ & $(.493)$ \\
\hline
\end{tabular}

NOTES: Based on linear probability models that account for the complex survey design. Propensity score-based weights are used to match the

distribution of observed characteristics of treatment and control groups. Robust, Huber-White corrected SEs shown in ( ) correct for correlation within

sampling units. ${ }^{*}=$ p-value $<=.10, * *<=.05, * * *=.01$. Models also include controls for race-gender specific national unemployment rate, national arrest

rate per 100,000 and national incarceration rate per 100,000 (coefficients not shown). Analyses are based on a sample size of 156,041. 
Table 4: Specification Check: Short-Run Results from Models with State Fixed Effects and State Time Trends Broad Substance Abuser Group, Time Period 1997-1998

\begin{tabular}{|c|c|c|c|c|c|c|c|}
\hline & SSI & Welfare & Employed & Full-time & Part-time & Disabled & In Labor Force \\
\hline $\operatorname{Pr}(\mathrm{SSI})$ & $2.47 * * *$ & $1.06^{* * *}$ & $-3.84 * * *$ & $-3.12 * * *$ & $-.828 * * *$ & $3.37 * * *$ & $-3.41 * * *$ \\
\hline (1994-1996) & $(.197)$ & $(.125)$ & $(.221)$ & $(.243)$ & $(.124)$ & $(.201)$ & $(.230)$ \\
\hline \multirow[t]{2}{*}{ After 1996} & $.017 *$ & -.005 & .019 & .019 & -.007 & -.0003 & .019 \\
\hline & $(.009)$ & $(.008)$ & $(.018)$ & $(.021)$ & $(.013)$ & $(.009)$ & $(.018)$ \\
\hline $\operatorname{Pr}(\mathrm{SSI}) *$ & .233 & -.134 & -.464 & -.417 & .064 & $.561 *$ & -.483 \\
\hline After 1996 & $(.282)$ & $(.188)$ & $(.310)$ & $(.344)$ & $(.166)$ & $(.341)$ & $(.339)$ \\
\hline \multirow[t]{2}{*}{ Treatment Group } & -.013 & -.013 & $.035 * * *$ & .009 & $.027 * *$ & .0001 & $.050 * * *$ \\
\hline & $(.007)$ & $(.008)$ & $(.014)$ & $(.016)$ & $(.012)$ & $(.008)$ & $(.013)$ \\
\hline \multirow[t]{2}{*}{ Tx*After 1996} & -.014 & .014 & $-.067 * * *$ & $-.045^{*}$ & $-.023 *$ & -.005 & $-.064 * * *$ \\
\hline & $(.011)$ & $(.012)$ & $(.023)$ & $(.026)$ & $(.014)$ & $(.011)$ & $(.022)$ \\
\hline \multirow[t]{2}{*}{$\operatorname{Pr}(\mathrm{SSI}) * \mathrm{Tx}$} & $.893 *$ & $.777 *$ & $-.930 * *$ & -.284 & $-.534 * *$ & -.122 & -.737 \\
\hline & $(.490)$ & $(.402)$ & $(.444)$ & $(.454)$ & $(.226)$ & $(.471)$ & $(.470)$ \\
\hline $\operatorname{Pr}(\mathrm{SSI}) *$ & $-1.53 * * *$ & -.499 & $1.60 * * *$ & 1.03 & .375 & -.332 & $1.54 * *$ \\
\hline Tx*After 1996 & $(.526)$ & $(.512)$ & $(.608)$ & $(.646)$ & $(.278)$ & $(.595)$ & $(.642)$ \\
\hline
\end{tabular}

NOTES: Based on linear probability models that account for the complex survey design. Propensity score-based weights are used to match the distribution of observed characteristics of treatment and control groups. Robust, Huber-White corrected SEs shown in ( ) correct for correlation within sampling units. ${ }^{*}=$ p-value $<=.10, * *<=.05, * * *<=.01$. Models also include state fixed effects and the following time-varying state characteristics: (1) whether the state had a major ADFC waiver approved; (2) whether TANF was officially implemented in the state; (3) the state unemployment rate; (4) the percent of all persons under age 65 in the state not covered by public or private insurance; (5) the percent of persons under age 65 in the state covered by Medicaid; and (6) the state incarceration rate. Analyses are based on a sample size of 52,363; only data from 1994-1998 are included in these analyses. 


\begin{tabular}{|c|c|c|c|c|c|c|}
\hline & \multicolumn{2}{|c|}{ Medicaid } & \multicolumn{2}{|c|}{ Private Insurance } & \multicolumn{2}{|c|}{ Any HI } \\
\hline & Broad & Narrow & Broad & Narrow & Broad & Narrow \\
\hline $\operatorname{Pr}(\mathrm{SSI})$ & $1.26 * * *$ & $1.25 * * *$ & $-2.28 * * *$ & $-2.19 * * *$ & $-.539 * * *$ & $-.493 * * *$ \\
\hline (1994-1996) & $(.115)$ & $(.125)$ & $(.143)$ & $(.148)$ & $(.117)$ & $(.138)$ \\
\hline After 1996 & $\begin{array}{l}-.030 * * * \\
(.009)\end{array}$ & $\begin{array}{l}-.038 * * * \\
(.012)\end{array}$ & $\begin{array}{l}.089 * * * \\
(.018)\end{array}$ & $\begin{array}{l}.070 * * * \\
(.024)\end{array}$ & $\begin{array}{l}.052 * * * \\
(.016)\end{array}$ & $\begin{array}{l}.035 \\
(.022)\end{array}$ \\
\hline After 1998 & $\begin{array}{l}.012 \\
(.009)\end{array}$ & $\begin{array}{l}.014 \\
(.014)\end{array}$ & $\begin{array}{l}-.012 \\
(.017)\end{array}$ & $\begin{array}{l}-.008 \\
(.023)\end{array}$ & $\begin{array}{l}.004 \\
(.014)\end{array}$ & $\begin{array}{l}.015 \\
(.018)\end{array}$ \\
\hline $\operatorname{Pr}(\mathrm{SSI}) *$ & .209 & .346 & -.040 & .045 & .240 & $.375^{*}$ \\
\hline After 1996 & $(.214)$ & $(.264)$ & $(.243)$ & $(.265)$ & $(.195)$ & $(.223)$ \\
\hline $\operatorname{Pr}(\mathrm{SSI}) *$ & -.203 & -.437 & .215 & .114 & -.102 & $-.356^{*}$ \\
\hline After 1998 & $(.219)$ & (.269) & $(.232)$ & $(.251)$ & (.169) & $(.191)$ \\
\hline Treatment Group & $\begin{array}{l}-.023 * * * \\
(.007)\end{array}$ & $\begin{array}{l}-.020 * * \\
(.009)\end{array}$ & $\begin{array}{l}-.006 \\
(.013)\end{array}$ & $\begin{array}{l}-.019 \\
(.018)\end{array}$ & $\begin{array}{l}-.030 * * * \\
(.011)\end{array}$ & $\begin{array}{l}-.041 * * \\
(.017)\end{array}$ \\
\hline Tx*After 1996 & $\begin{array}{l}.025 * * \\
(.011)\end{array}$ & $\begin{array}{l}.032 * * \\
(.014)\end{array}$ & $\begin{array}{l}-.042 * * \\
(.021)\end{array}$ & $\begin{array}{l}-.032 \\
(.033)\end{array}$ & $\begin{array}{l}-.010 \\
(.020)\end{array}$ & $\begin{array}{c}.012 \\
(.028)\end{array}$ \\
\hline Tx*After 1998 & $\begin{array}{l}-.002 \\
(.009)\end{array}$ & $\begin{array}{l}.0002 \\
(.014)\end{array}$ & $\begin{array}{l}.005 \\
(.019)\end{array}$ & $\begin{array}{l}-.011 \\
(.029)\end{array}$ & $\begin{array}{l}.0004 \\
(.018)\end{array}$ & $\begin{array}{r}-.013 \\
(.025)\end{array}$ \\
\hline $\operatorname{Pr}(\mathrm{SSI}) * \mathrm{Tx}$ & $\begin{array}{l}.504^{*} \\
(.270)\end{array}$ & $\begin{array}{l}.509 \\
(.352)\end{array}$ & $\begin{array}{l}-.440 \\
(.291)\end{array}$ & $\begin{array}{l}-.424 \\
(.388)\end{array}$ & $\begin{array}{l}-.031 \\
(.242)\end{array}$ & $\begin{array}{c}.107 \\
(.306)\end{array}$ \\
\hline $\begin{array}{l}\operatorname{Pr}(\mathrm{SSI}) * \text { Tx*After } \\
1996\end{array}$ & $\begin{array}{l}-.562 \\
(.405)\end{array}$ & $\begin{array}{l}-.678 \\
(.510)\end{array}$ & $\begin{array}{l}.537 \\
(.480)\end{array}$ & $\begin{array}{l}.074 \\
(.546)\end{array}$ & $\begin{array}{l}-.133 \\
(.402)\end{array}$ & $\begin{array}{l}-.580 \\
(.530)\end{array}$ \\
\hline $\begin{array}{l}\operatorname{Pr}(\mathrm{SSI}) * \text { Tx*After } \\
1998\end{array}$ & $\begin{array}{l}.236 \\
(.354)\end{array}$ & $\begin{array}{l}.495 \\
(.489)\end{array}$ & $\begin{array}{l}-.183 \\
(.453)\end{array}$ & $\begin{array}{l}.286 \\
(.481)\end{array}$ & $\begin{array}{l}.089 \\
(.353)\end{array}$ & $\begin{array}{l}.644 \\
(.468)\end{array}$ \\
\hline
\end{tabular}

NOTES: Based on linear probability models that account for the complex survey design. Propensity scorebased weights are used to match observed characteristics between treatment and control groups. Robust, Huber-White corrected SEs shown in ( ) correct for correlation within sampling units. * ${ }^{*}$-value $<=.10$, $* *<=.05, * * *<=.01$. Models also include controls for race-gender specific national unemployment rate, national arrest rate per 100,000 and national incarceration rate per 100,000 (coefficients not shown). Analyses are based on a sample size of 156,041 . 
Table 6: Health Care Utilization and Arrests in Last Year

\begin{tabular}{|c|c|c|c|c|c|c|c|c|c|c|}
\hline Outcome: & \multicolumn{4}{|c|}{$\begin{array}{c}\text { Hospital } \\
\text { admission }\end{array}$} & \multicolumn{2}{|c|}{ Psychiatric visit } & \multicolumn{2}{|c|}{ Psych. admission $^{\text {A }}$} & \multicolumn{2}{|c|}{ Arrested/booked } \\
\hline $\operatorname{Pr}(\mathrm{SSI})$ & $1.01 * * *$ & $.868 * * *$ & $.842 * * *$ & $.748 * * *$ & $.549 * * *$ & $.656 * * *$ & $.096 * * *$ & $.108 * * *$ & .014 & .027 \\
\hline \multirow[t]{2}{*}{ After 1996} & $-.048 * * *$ & $-.040 * *$ & .0006 & .007 & $-.019 * *$ & $-.027 *$ & -.0003 & -.0002 & -.004 & -.004 \\
\hline & $(.014)$ & $(.018)$ & $(.010)$ & $(.014)$ & $(.010)$ & $(.014)$ & $(.003)$ & $(.006)$ & $(.008)$ & $(.018)$ \\
\hline After 1998 & $.034 * *$ & .031 & $.027 * * *$ & $.032 * *$ & -.013 & -.014 & & & $.048 * * *$ & $.062 * * *$ \\
\hline After 1996 & $(.207)$ & $(.224)$ & $(.178)$ & $(.187)$ & $(.158)$ & $(.203)$ & $(.067)$ & $(.093)$ & $(.070)$ & $(.087)$ \\
\hline $\operatorname{Pr}(\mathrm{SSI}) *$ & .138 & .229 & -.077 & -.223 & -.185 & $-.285^{*}$ & & & $.202 * * *$ & $.271 * * *$ \\
\hline After 1998 & $(.173)$ & $(.196)$ & $(.151)$ & $(.165)$ & $(.138)$ & $(.153)$ & & & $(.077)$ & $(.086)$ \\
\hline \multirow[t]{2}{*}{ Treatment Group } & $.024 * *$ & $.042 * * *$ & -.013 & -.008 & .008 & $.027 * *$ & .001 & .005 & $.041 * * *$ & $.085^{* * *}$ \\
\hline & $(.012)$ & $(.016)$ & $(.009)$ & $(.011)$ & $(.008)$ & $(.012)$ & $(.003)$ & $(.005)$ & $(.006)$ & $(.015)$ \\
\hline Tx*After 1996 & .001 & -.015 & .006 & .012 & .020 & .018 & -.005 & -.004 & .007 & -.002 \\
\hline $\mathrm{Tx}$ & $(.262)$ & $(.332)$ & $(.256)$ & $(.369)$ & $(.198)$ & $(.303)$ & $(.109)$ & $(.188)$ & $(.111)$ & $(.159)$ \\
\hline $\operatorname{Pr}(\mathrm{SSI}) *$ & .367 & .573 & .181 & -.094 & -.285 & -.402 & .258 & .164 & .045 & .344 \\
\hline Tx*After 1996 & $(.450)$ & $(.577)$ & $(.335)$ & $(.509)$ & $(.320)$ & $(.427)$ & $(.216)$ & $(.314)$ & $(.186)$ & $(.288)$ \\
\hline $\operatorname{Pr}(\mathrm{SSI})^{*}$ & -.188 & -.211 & .162 & .326 & .211 & .271 & & & .279 & .130 \\
\hline Tx*After 1998 & $(.429)$ & $(.505)$ & $(.327)$ & $(.410)$ & $(.276)$ & $(.356)$ & & & $(.201)$ & $(.316)$ \\
\hline
\end{tabular}

NOTES: Based on linear probability models that account for the complex survey design. Propensity score-based weights are used to match observed characteristics between treatment and control groups. Robust, Huber-White corrected SEs shown in ( ) correct for correlation within sampling units. $*=\mathrm{p}$-value $<=.10, * *<=.05, * * *<=.01$. Models also include controls for race-gender specific national unemployment rate, national arrest rate per

100,000 and national incarceration rate per 100,000 (coefficients not shown). Analyses are based on a sample size of 156,041 . 
Figure 1: Trends in SSA caseload among Mental Health and DA\&A Population

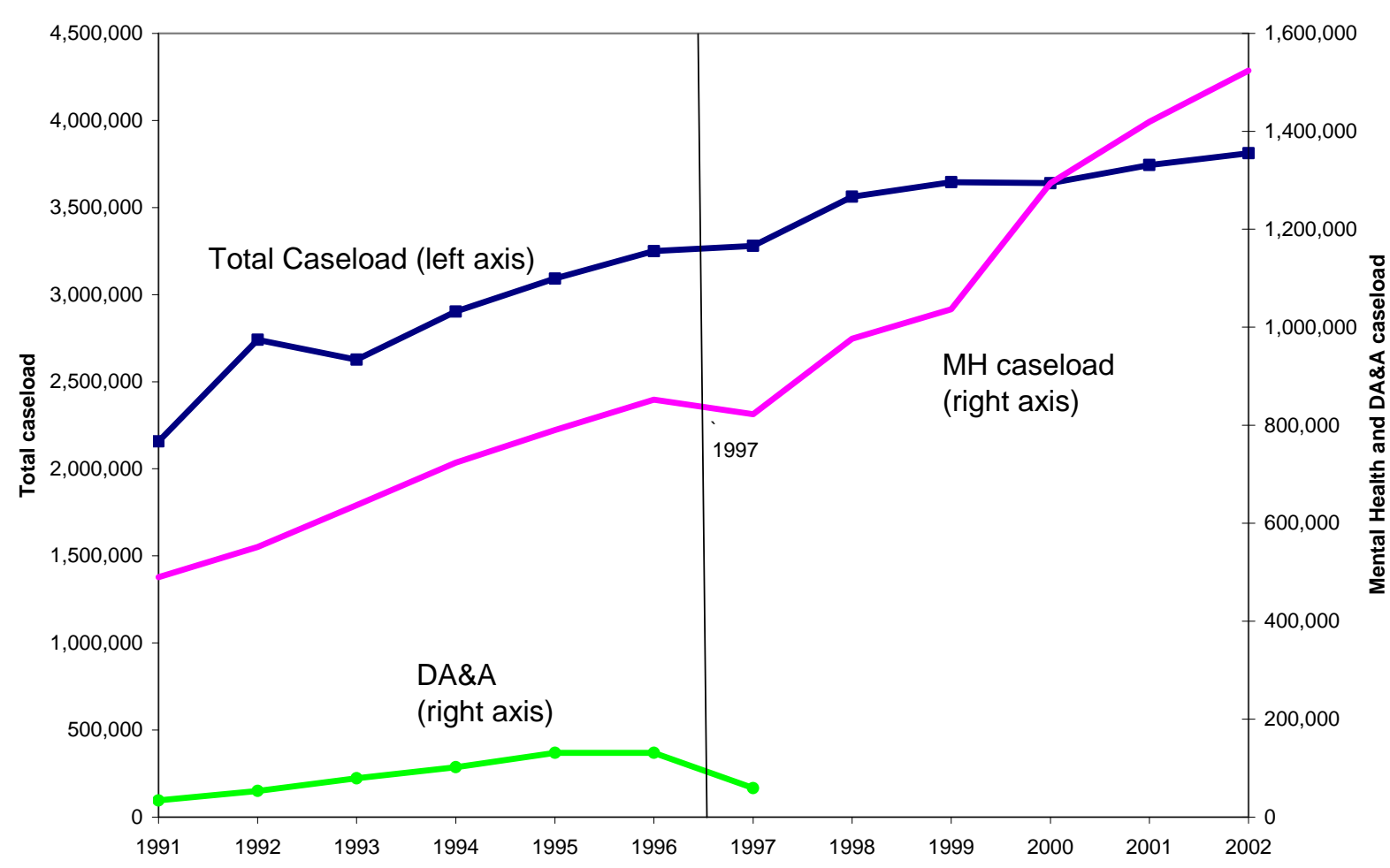

Sources for Figure 1: for Total and Mental Health Caseload: Social Security Administration, Social Security Bulletin, Annual Statistical Supplement, 1991-2004 (Washington: Government Printing Office, 1991-2004). For DA\&A population: Barber, S.L. Supplemental Security Income for whom Alcoholism and Drug Addiction Provisions Apply (DA\&A Recipients). (Washington: Office of Program Benefits Policy, 1996) and for 1996, 1997 DA\&A figures :Schmidt, Lucie. 2004. Effects of Welfare Reform on the Supplemental Security Income (SSI) Program, Policy Brief \#4, National Poverty Center (available at http://www.npc.umich.edu/publications/policy_briefs/brief4/brief4.pdf) 
Figure 2: Trends in SSI and Employment, by Year
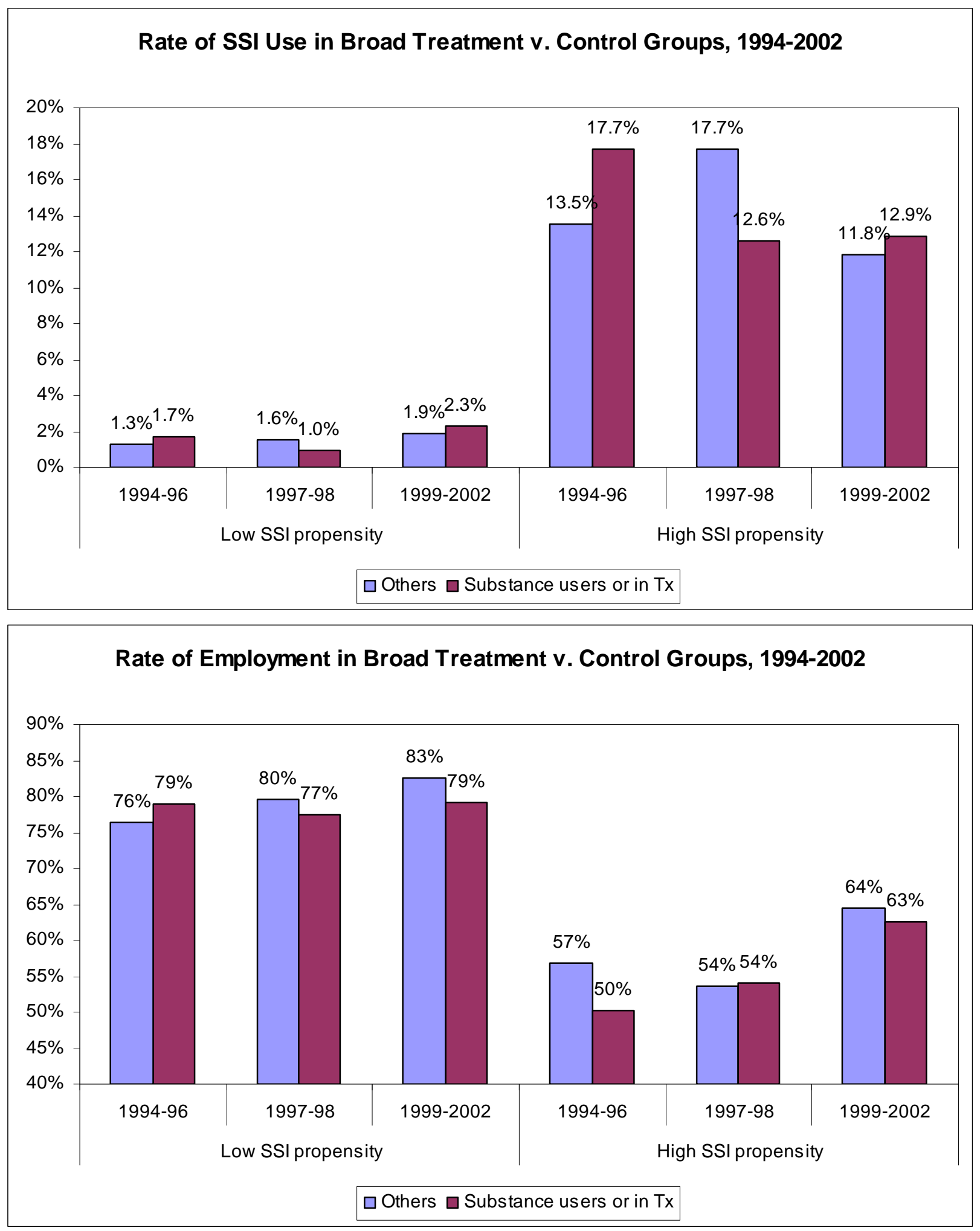


\section{Appendix}

Symptoms of Substance Abuse

Starting in 1999, the survey includes the following six criteria, pertaining to the previous 12 month period: 1) having a period of at least a month during which a great deal of time was spent getting the drug, using the drug, or getting over its effects; 2) building up a tolerance for the drug so that the same amount of the drug had less effect than before; 3) using the drug much more often or in larger amounts than intended; 4) use of the drug often preventing going to work or school, taking care of children, or engaging in recreational activities; 5) the drug causing emotional or psychological problems (such as feeling uninterested, depressed, suspicious or paranoid, or having strange ideas) or health problems (such as liver or stomach disease, pancreatitis, feet tingling, numbness, memory problems, an accidental overdose, a persistent cough, a seizure or fit, hepatitis, or abscesses); and 6) wanting or trying to stop or cut down use of the drug but being unable to do so. The survey items used to capture symptoms of substance disorder changed somewhat. We dealt with this issue by using the six symptoms listed above which are fairly consistent across all years.

Appendix Table 1: Sources for state policies, insurance coverage, and incarceration rates.

\begin{tabular}{|c|c|c|}
\hline Variable & Definition of variable & Source \\
\hline $\begin{array}{l}\text { Welfare } \\
\text { waiver }\end{array}$ & $\begin{array}{l}\text { Ranges from } 0 \text { to } 1 . \\
\text { Share of year in which } \\
\text { state had welfare } \\
\text { waiver in effect. }\end{array}$ & $\begin{array}{l}\text { Crouse, Gil. (1999). "State Implementation of Major } \\
\text { Changes to Welfare Policies, } 1992-1998 . " \text { Office of } \\
\text { Human Services Policy, Assistant Secretary for Planning } \\
\text { and Evaluation, U.S. Department of Health and Human } \\
\text { Services. Accessed on 9/18/2008 at } \\
\text { http://aspe.hhs.gov/HSP/Waiver-Policies99/Table_A.htm. }\end{array}$ \\
\hline $\begin{array}{l}\text { Insurance } \\
\text { coverage }\end{array}$ & $\begin{array}{l}\text { Share of population } \\
\text { under age } 65 \text { with } \\
\text { health insurance for } \\
\text { part of the year. }\end{array}$ & $\begin{array}{l}\text { U.S. Census Bureau. "Table HI-6. Health Insurance } \\
\text { Coverage Status and Type of Coverage by State-- People } \\
\text { Under 65: } 1987 \text { to 2005." Compiled by US Census Bureau } \\
\text { based on data from the Current Population Survey, 1988- } \\
2006 \text { Annual Social and Economic Supplements. Accessed } \\
\text { on 9/19/2008 at http://www.census.gov/hhes/www/hlthins/ } \\
\text { historic/hlthin05/hihistt6.html. }\end{array}$ \\
\hline $\begin{array}{l}\text { Incarceration } \\
\text { rates }\end{array}$ & $\begin{array}{l}\text { Prisoners sentenced to } \\
\text { more than a year, per } \\
100,000 \text { population }\end{array}$ & $\begin{array}{l}\text { U.S. Department of Justice, Office of Justice Programs, } \\
\text { Bureau of Justice Statistics, 2004. "Prisoners under State or } \\
\text { Federal jurisdiction, Federal and State-by-State, 1977- } \\
\text { 2004." Crime \& Justice Electronic Data Abstracts. } \\
\text { Accessed on 9/19/2008 at } \\
\text { http://www.ojp.usdoj.gov/bjs/dtdata.htm\#corrections }\end{array}$ \\
\hline
\end{tabular}


Information regarding welfare reform comes from the Office of Human Services Policy at the Department of Health and Human Services (DHHS, 2007). States that implemented a waiver or TANF on the first of the year, and states that did not implement a waiver of TANF policy at all in that year, were assigned a dummy variable ( 1 if yes, 0 if no) indicating the policy was in effect, or was not in effect during the entire year. In cases where a state implemented a policy change mid-year, the state was assigned a value corresponding to the portion of the year in which the policy was in effect - for example, a state that implemented a waiver on July 1 was assigned a .5 for that year. ${ }^{9}$ Insurance coverage rates come from the Housing and Household Economic Statistics Division of the US Census Bureau. Incarceration rates come from the Bureau of Justice Statistics.

\footnotetext{
${ }^{9}$ States that implemented policies prior to the $15^{\text {th }}$ of the month were treated as if the policy were not in effect during that month, while states that implemented policies on the $15^{\text {th }}$ or later were treated as if the policy were in effect during the entire month.
} 
Appendix Table 2: Weighted Summary Statistics

\begin{tabular}{|c|c|c|c|c|c|c|c|}
\hline \multirow[b]{2}{*}{ Covariates: } & & \multicolumn{2}{|c|}{ Pre-Period: 1994-1996 } & \multicolumn{2}{|c|}{$1997-1998$} & \multicolumn{2}{|c|}{ 1999-2002 } \\
\hline & & $\begin{array}{c}\text { Substance } \\
\text { abuser } \\
n=5,756\end{array}$ & $\begin{array}{c}\text { Others } \\
\mathrm{n}=21,950\end{array}$ & $\begin{array}{c}\text { Substance } \\
\text { abuser } \\
\mathrm{n}=4,517\end{array}$ & $\begin{array}{c}\text { Others } \\
\mathrm{n}=20,140\end{array}$ & $\begin{array}{c}\text { Substance } \\
\text { abuser } \\
\mathrm{n}=20,123\end{array}$ & $\begin{array}{c}\text { Others } \\
\mathrm{n}=83,555\end{array}$ \\
\hline \multicolumn{8}{|l|}{ Covariates: } \\
\hline Sex & Female & 0.415 & 0.415 & 0.397 & 0.394 & 0.403 & 0.405 \\
\hline \multirow[t]{7}{*}{ Age } & $18-21$ & 0.152 & 0.152 & 0.178 & 0.154 & 0.199 & 0.159 \\
\hline & $22-23$ & 0.061 & 0.061 & 0.066 & 0.063 & 0.068 & 0.060 \\
\hline & $24-25$ & 0.056 & 0.056 & 0.050 & 0.054 & 0.050 & 0.049 \\
\hline & $26-29$ & 0.104 & 0.104 & 0.103 & 0.101 & 0.097 & 0.086 \\
\hline & $30-34$ & 0.142 & 0.142 & 0.135 & 0.130 & 0.114 & 0.114 \\
\hline & $35-49$ & 0.360 & 0.360 & 0.337 & 0.361 & 0.339 & 0.382 \\
\hline & $50-64$ & 0.125 & 0.125 & 0.131 & 0.136 & 0.133 & 0.151 \\
\hline \multirow{10}{*}{ Education } & 5 or fewer & 0.011 & 0.011 & 0.017 & 0.009 & 0.015 & 0.012 \\
\hline & 6 & 0.009 & 0.009 & 0.010 & 0.009 & 0.012 & 0.008 \\
\hline & 7 & 0.011 & 0.011 & 0.007 & 0.008 & 0.007 & 0.007 \\
\hline & 8 & 0.017 & 0.017 & 0.013 & 0.014 & 0.020 & 0.014 \\
\hline & 9 & 0.033 & 0.033 & 0.026 & 0.028 & 0.037 & 0.029 \\
\hline & 10 & 0.055 & 0.055 & 0.046 & 0.048 & 0.050 & 0.046 \\
\hline & 11 & 0.078 & 0.078 & 0.090 & 0.081 & 0.088 & 0.082 \\
\hline & 12 & 0.452 & 0.452 & 0.457 & 0.432 & 0.406 & 0.459 \\
\hline & 13 & 0.097 & 0.097 & 0.118 & 0.111 & 0.131 & 0.112 \\
\hline & $14-15$ & 0.236 & 0.236 & 0.216 & 0.257 & 0.234 & 0.233 \\
\hline \multirow[t]{4}{*}{ Marital Status } & Married & 0.486 & 0.486 & 0.459 & 0.475 & 0.386 & 0.447 \\
\hline & Widowed & 0.015 & 0.015 & 0.016 & 0.019 & 0.018 & 0.019 \\
\hline & Divorced & 0.159 & 0.159 & 0.137 & 0.145 & 0.161 & 0.177 \\
\hline & Never Married & 0.340 & 0.340 & 0.388 & 0.361 & 0.435 & 0.356 \\
\hline \multirow[t]{4}{*}{ Race/Ethnicity } & White & 0.723 & 0.723 & 0.728 & 0.709 & 0.694 & 0.693 \\
\hline & Black & 0.134 & 0.134 & 0.125 & 0.133 & 0.134 & 0.132 \\
\hline & Latino & 0.114 & 0.114 & 0.115 & 0.121 & 0.134 & 0.129 \\
\hline & Other & 0.029 & 0.029 & 0.032 & 0.037 & 0.038 & 0.044 \\
\hline Language & Spanish speaker & 0.036 & 0.036 & 0.034 & 0.039 & 0.044 & 0.042 \\
\hline Military Veteran & & 0.155 & 0.155 & 0.152 & 0.150 & 0.108 & 0.139 \\
\hline Health & Poor & 0.024 & 0.024 & 0.017 & 0.022 & 0.024 & 0.022 \\
\hline
\end{tabular}




\begin{tabular}{|c|c|c|c|c|c|c|c|}
\hline & Fair & 0.081 & 0.081 & 0.082 & 0.085 & 0.100 & 0.083 \\
\hline & Good & 0.275 & 0.275 & 0.245 & 0.271 & 0.288 & 0.303 \\
\hline & Very Good & 0.340 & 0.340 & 0.364 & 0.345 & 0.363 & 0.365 \\
\hline & Excellent & 0.278 & 0.278 & 0.292 & 0.276 & 0.225 & 0.226 \\
\hline \multirow[t]{4}{*}{ Prior substance use } & Lifetime use of illicit drugs & 0.604 & 0.604 & 0.668 & 0.628 & 0.781 & 0.687 \\
\hline & Alcohol before age 15 & 0.254 & 0.254 & 0.253 & 0.248 & 0.342 & 0.279 \\
\hline & Marijuana before age 17 & 0.271 & 0.271 & 0.308 & 0.290 & 0.406 & 0.319 \\
\hline & Smoke daily & 0.641 & 0.641 & 0.673 & 0.637 & 0.587 & 0.633 \\
\hline \multirow[t]{6}{*}{ Household Size } & 1 & 0.086 & 0.086 & 0.102 & 0.092 & 0.115 & 0.087 \\
\hline & 2 & 0.291 & 0.291 & 0.292 & 0.295 & 0.257 & 0.287 \\
\hline & 3 & 0.223 & 0.223 & 0.228 & 0.210 & 0.229 & 0.224 \\
\hline & 4 & 0.219 & 0.219 & 0.192 & 0.215 & 0.215 & 0.220 \\
\hline & 5 & 0.111 & 0.111 & 0.093 & 0.105 & 0.102 & 0.110 \\
\hline & 6 or More & 0.071 & 0.071 & 0.079 & 0.071 & 0.082 & 0.071 \\
\hline \multirow[t]{3}{*}{ Urbanicity } & In MSA $>1$ million & 0.421 & 0.421 & 0.390 & 0.402 & 0.446 & 0.418 \\
\hline & In MSA $<1$ million & 0.344 & 0.344 & 0.367 & 0.377 & 0.339 & 0.355 \\
\hline & Not in MSA & 0.235 & 0.235 & 0.243 & 0.222 & 0.214 & 0.227 \\
\hline
\end{tabular}

NOTES: ${ }^{A}$ Sample limited to respondents with $<16$ years of education \& percentages reflect both sampling and propensity-score based weights to balance treatment and control group in pre-period. ${ }^{\mathrm{B}}$ Broad Treatment $=$ respondents reporting moderate/heavy substance use, $3+$ symptoms of disorder, and/or substance treatment (including self-help groups) in last year. "moderate to heavy use"= any of the following: a) an individual "binges" (5 or more alcoholic beverages are consumed at one sitting) $>=3$ times/month; b) an individual uses marijuana $>=6$ times/ year; or c) an individual uses any illicit drug other than marijuana $>=3$ times/year. The " 3 or more symptoms" = person has $>=3$ of 6 symptoms for at least one single substance, based on questions regarding 10 substances including alcohol. ${ }^{\mathrm{C}}$ Information on mental health inpatient stays is not available in a usable format for the second post period. ${ }^{\mathrm{D}}$ Employment measure is based on "present work status." ${ }^{\mathrm{E}}$ Health insurance variables refer to coverage at time of the survey (or in the survey month). 


\begin{tabular}{|c|c|c|c|c|c|c|c|c|c|c|}
\hline \multicolumn{11}{|c|}{ Appendix Table 3: Public Program Participation and Health Insurance, Logit Models } \\
\hline & Broad & Narrow & Broad & Narrow & Broad & Narrow & Broad & Narrow & Broad & Narrow \\
\hline \multirow[t]{2}{*}{$\operatorname{Pr}(\mathrm{SSI})(1994-1996)$} & $19.17 * * *$ & $18.38^{* * *}$ & $4.48^{* * *}$ & $4.53 * * *$ & $10.39 * * *$ & $10.20 * * *$ & $-9.95 * * *$ & $-9.44 * * *$ & $-2.74 * * *$ & -2.34 \\
\hline & $(1.04)$ & $(1.22)$ & $(0.78)$ & $(0.87)$ & $(0.66)$ & $(0.70)$ & $(0.70)$ & $(0.74)$ & $(0.55)$ & $(0.62)$ \\
\hline \multirow[t]{2}{*}{ After 1996} & $0.73 * *$ & $0.77^{*}$ & $-0.38 * * *$ & $-0.47 * * *$ & $-0.50 * * *$ & $-0.55 * * *$ & $0.43 * * *$ & $0.31 * * *$ & $0.29 * * *$ & 0.18 \\
\hline & $(0.34)$ & $(0.47)$ & $(0.14)$ & $(0.18)$ & $(0.15)$ & $(0.18)$ & $(0.09)$ & $(0.11)$ & $(0.09)$ & $(0.11)$ \\
\hline \multirow[t]{2}{*}{ After 1998} & $0.56 * * *$ & $0.59 * *$ & 0.25 & 0.16 & 0.21 & 0.20 & -0.06 & -0.04 & 0.02 & 0.08 \\
\hline & $(0.21)$ & $(0.30)$ & $(0.18)$ & $(0.24)$ & $(0.14)$ & $(0.18)$ & $(0.08)$ & $(0.10)$ & $(0.08)$ & $(0.09)$ \\
\hline \multirow[t]{2}{*}{$\operatorname{Pr}(\mathrm{SSI}) *$ After 1996} & -0.53 & -0.29 & -1.38 & -1.27 & $2.61 * *$ & $3.22 * *$ & -0.20 & 0.32 & 1.03 & 1.71 \\
\hline & $(1.61)$ & $(2.19)$ & $(1.30)$ & $(1.52)$ & $(1.22)$ & $(1.41)$ & $(1.14)$ & $(1.25)$ & $(0.99)$ & $(1.07)$ \\
\hline \multirow[t]{2}{*}{$\operatorname{Pr}(\mathrm{SSI}) *$ After1998 } & $-2.93 * *$ & -2.79 & $2.47 * *$ & 2.13 & -1.75 & $-3.05 * *$ & 1.07 & 0.56 & -0.60 & $-1.80 *$ \\
\hline & $(1.46)$ & $(1.89)$ & $(1.20)$ & $(1.41)$ & $(1.23)$ & $(1.45)$ & $(1.06)$ & $(1.15)$ & $(0.90)$ & $(0.95)$ \\
\hline \multirow[t]{2}{*}{ Broad Substance Abuser Group } & 0.16 & & -0.14 & & $-0.35 * * *$ & & -0.02 & & $-0.17 * * *$ & \\
\hline & $(0.32)$ & & $(0.11)$ & & $(0.11)$ & & $(0.07)$ & & $(0.06)$ & \\
\hline \multicolumn{2}{|l|}{ Narrow Substance Abuser Group } & 0.41 & & -0.02 & & $-0.24 * *$ & & -0.07 & & $-0.21 * * *$ \\
\hline & & $(0.45)$ & & $(0.14)$ & & $(0.12)$ & & $(0.08)$ & & $(0.08)$ \\
\hline \multirow{2}{*}{ Broad Group*After 1996} & -0.71 & & $0.35^{*}$ & & $0.36 * *$ & & $-0.21 * *$ & & -0.06 & \\
\hline & $(0.47)$ & & $(0.20)$ & & $(0.16)$ & & $(0.10)$ & & $(0.11)$ & \\
\hline \multicolumn{2}{|l|}{ Narrow Group*After 1996} & -0.74 & & 0.41 & & $0.42 * *$ & & -0.15 & & 0.05 \\
\hline & & $(0.71)$ & & $(0.26)$ & & $(0.20)$ & & $(0.15)$ & & $(0.14)$ \\
\hline \multirow[t]{2}{*}{ Broad Group*After 1998} & $0.74 * *$ & & -0.05 & & 0.05 & & 0.03 & & 0.00 & \\
\hline & $(0.33)$ & & $(0.19)$ & & $(0.14)$ & & $(0.09)$ & & $(0.10)$ & \\
\hline \multicolumn{2}{|l|}{ Narrow Group*After1998 } & 0.84 & & -0.02 & & 0.11 & & -0.05 & & -0.07 \\
\hline & & $(0.54)$ & & $(0.24)$ & & $(0.19)$ & & $(0.13)$ & & $(0.12)$ \\
\hline \multirow[t]{2}{*}{$\operatorname{Pr}(\mathrm{SSI}) *$ Broad Group } & 0.80 & & $2.94 *$ & & $4.11 * * *$ & & -2.30 & & 0.05 & \\
\hline & $(2.45)$ & & $(1.59)$ & & $(1.49)$ & & $(1.60)$ & & $(1.11)$ & \\
\hline \multirow[t]{2}{*}{$\operatorname{Pr}(\mathrm{SSI}) *$ Narrow Group } & & 1.46 & & 1.74 & & $3.56^{* *}$ & & -2.37 & & 0.62 \\
\hline & & $(3.19)$ & & $(1.77)$ & & $(1.80)$ & & $(2.26)$ & & $(1.35)$ \\
\hline \multirow[t]{2}{*}{$\operatorname{Pr}(\mathrm{SSI}) *$ Broad Group*After 1996} & -0.48 & & -0.50 & & $-4.48 *$ & & 2.92 & & -0.57 & \\
\hline & $(3.41)$ & & $(2.52)$ & & $(2.33)$ & & $(2.39)$ & & $(1.89)$ & \\
\hline \multicolumn{2}{|l|}{ Pr(SSI)*Narrow Group*After1996 } & -1.05 & & -0.23 & & $-5.13 *$ & & 0.46 & & -2.65 \\
\hline & & $(5.12)$ & & $(3.09)$ & & $(2.84)$ & & $(3.01)$ & & $(2.37)$ \\
\hline $\operatorname{Pr}(\mathrm{SSI}) *$ Broad Group*After 1998 & -1.20 & & $-4.53 * *$ & & 0.82 & & -0.83 & & 0.47 & \\
\hline
\end{tabular}




\begin{tabular}{|c|c|c|c|c|c|c|c|c|c|c|}
\hline & $(2.65)$ & & $(2.35)$ & & $(1.99)$ & & $(2.12)$ & & $(1.70)$ & \\
\hline $\operatorname{Pr}(\mathrm{SSI}) *$ Narrow Group*After 1998 & & -2.60 & & $-6.12 *$ & & 1.82 & & 1.59 & & 3.02 \\
\hline & & $(4.00)$ & & $(3.35)$ & & $(2.69)$ & & $(2.48)$ & & $(2.11)$ \\
\hline DDD 1997-1998 v. 1994-1996 & $\begin{array}{l}-0.075 * * \\
(0.036)\end{array}$ & $\begin{array}{l}-0.080 * \\
(0.049)\end{array}$ & $\begin{array}{l}-0.004 \\
(0.016)\end{array}$ & $\begin{array}{c}0.000 \\
(0.023)\end{array}$ & $\begin{array}{l}-0.069 \\
(0.050)\end{array}$ & $\begin{array}{l}-0.080 \\
(0.066)\end{array}$ & $\begin{array}{c}0.055 \\
(0.054)\end{array}$ & $\begin{array}{c}0.000 \\
(0.062)\end{array}$ & $\begin{array}{l}-0.012 \\
(0.045)\end{array}$ & $\begin{array}{l}\mathbf{- 0 . 0 5 7} \\
\mathbf{( 0 . 0 5 3 )}\end{array}$ \\
\hline DDD 1999-2002 v. 1994-1996 ${ }^{B}$ & $\begin{array}{l}-0.024 \\
(0.033)\end{array}$ & $\begin{array}{l}-0.053 \\
(0.037)\end{array}$ & $\begin{array}{l}-0.031 * * \\
(0.013)\end{array}$ & $\begin{array}{l}-0.037^{* *} \\
(0.019)\end{array}$ & $\begin{array}{l}-\mathbf{0 . 0 4 7} \\
(0.036)\end{array}$ & $\begin{array}{l}-0.032 \\
(0.052)\end{array}$ & $\begin{array}{c}0.035 \\
(0.040)\end{array}$ & $\begin{array}{c}0.033 \\
(0.045)\end{array}$ & $\begin{array}{l}-0.003 \\
(0.035)\end{array}$ & $\begin{array}{c}0.006 \\
(0.044)\end{array}$ \\
\hline DDD 1999-2002 v. 1997-1998 ${ }^{B}$ & $\begin{array}{c}0.050 * \\
(0.031)\end{array}$ & $\begin{array}{c}0.031 \\
(0.040)\end{array}$ & $\begin{array}{l}-0.028 * \\
(0.015)\end{array}$ & $\begin{array}{l}-0.038 * * \\
(0.018)\end{array}$ & $\begin{array}{c}0.022 \\
(0.038)\end{array}$ & $\begin{array}{c}0.047 \\
(0.052)\end{array}$ & $\begin{array}{l}-0.020 \\
(0.051)\end{array}$ & $\begin{array}{c}0.033 \\
(0.058)\end{array}$ & $\begin{array}{l}0.008 \\
(0.037)\end{array}$ & $\begin{array}{c}0.063 \\
(0.046)\end{array}$ \\
\hline
\end{tabular}

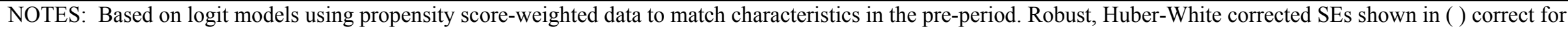

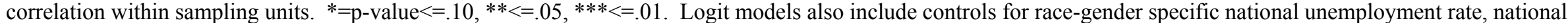

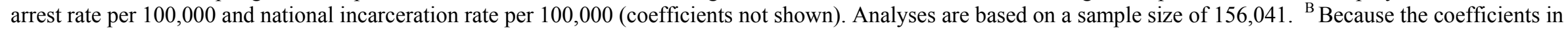

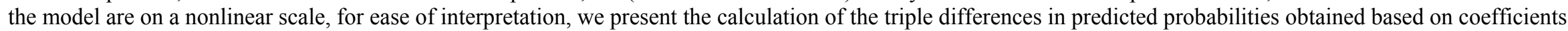

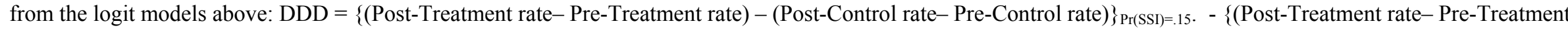

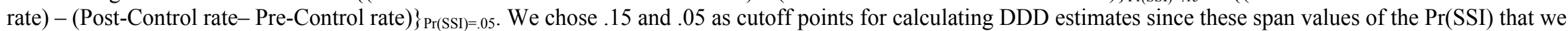
observe in our data. Standard errors on DDD estimates are bootstrapped using 100 replications. 


\begin{tabular}{|c|c|c|c|c|c|c|c|c|c|c|}
\hline \multicolumn{11}{|c|}{ Appendix Table 4: Labor Market Outcomes, Logit Models } \\
\hline & Broad & Narrow & Broad & Narrow & Broad & Narrow & Broad & Narrow & Broad & Narrow \\
\hline \multirow[t]{2}{*}{$\operatorname{Pr}(\mathrm{SSI})(1994-1996)$} & $-8.54 * * *$ & $-8.08 * * *$ & $-6.76 * * *$ & $-5.96 * * *$ & $-3.41 * * *$ & $-3.91 * * *$ & $19.82 * * *$ & $18.79 * * *$ & $-8.89 * * *$ & $-8.40 * * *$ \\
\hline & $(0.65)$ & $(0.71)$ & $(0.69)$ & $(0.74)$ & $(0.92)$ & $(0.94)$ & $(0.93)$ & $(1.01)$ & $(0.68)$ & $(0.75)$ \\
\hline \multirow[t]{2}{*}{ After 1996} & $0.17 *$ & $0.25^{*}$ & 0.14 & $0.22 *$ & -0.04 & -0.03 & 0.22 & 0.24 & 0.11 & 0.14 \\
\hline & $(0.10)$ & $(0.13)$ & $(0.09)$ & $(0.12)$ & $(0.12)$ & $(0.12)$ & $(0.32)$ & $(0.37)$ & $(0.12)$ & $(0.16)$ \\
\hline \multirow[t]{2}{*}{ After 1998} & $0.16^{*}$ & 0.14 & 0.03 & 0.02 & $-0.21 * *$ & -0.16 & $0.45^{*}$ & 0.50 & 0.10 & 0.01 \\
\hline & $(0.09)$ & $(0.11)$ & $(0.08)$ & $(0.11)$ & $(0.10)$ & $(0.14)$ & $(0.27)$ & $(0.33)$ & $(0.09)$ & $(0.12)$ \\
\hline \multirow[t]{2}{*}{$\operatorname{Pr}(\mathrm{SSI}) *$ After 1996} & $-2.27 * *$ & $-2.28 *$ & $-1.65^{*}$ & -1.48 & -1.07 & -2.02 & $3.02 *$ & $3.53^{*}$ & $-2.26^{* *}$ & $-2.75 * *$ \\
\hline & $(0.93)$ & $(1.21)$ & $(0.99)$ & $(1.20)$ & $(1.72)$ & $(1.61)$ & (1.69) & $(2.06)$ & $(0.98)$ & $(1.25)$ \\
\hline \multirow[t]{2}{*}{ Pr(SSI)*After1998 } & $1.69 * *$ & $2.57 * *$ & $2.43 * * *$ & $2.72 * * *$ & -1.28 & 1.18 & $-2.63 *$ & -2.74 & $1.57^{*}$ & $2.48 * *$ \\
\hline & $(0.85)$ & $(1.07)$ & $(0.88)$ & $(1.06)$ & $(1.57)$ & $(1.55)$ & $(1.52)$ & $(1.85)$ & $(0.91)$ & $(1.14)$ \\
\hline \multirow[t]{2}{*}{ Broad Substance Abuser Group } & $0.21 * * *$ & & 0.07 & & $0.23 * * *$ & & $-0.53 * * *$ & & $0.35 * * *$ & \\
\hline & $(0.08)$ & & $(0.06)$ & & $(0.09)$ & & $(0.19)$ & & $(0.09)$ & \\
\hline \multicolumn{2}{|l|}{ Narrow Substance Abuser Group } & 0.05 & & -0.05 & & $0.25 * *$ & & -0.31 & & 0.13 \\
\hline & & $(0.12)$ & & $(0.09)$ & & $(0.12)$ & & $(0.25)$ & & $(0.14)$ \\
\hline \multirow[t]{2}{*}{ Broad Group*After 1996} & $-0.36^{* * *}$ & & $-0.21 * *$ & & -0.18 & & -0.40 & & $-0.42 * * *$ & \\
\hline & $(0.13)$ & & $(0.11)$ & & $(0.12)$ & & $(0.39)$ & & $(0.15)$ & \\
\hline \multicolumn{2}{|l|}{ Narrow Group*After 1996} & $-0.42 * * *$ & & $-0.26^{*}$ & & -0.22 & & $-1.13 * *$ & & $-0.54 * * *$ \\
\hline & & $(0.17)$ & & $(0.15)$ & & $(0.19)$ & & $(0.52)$ & & $(0.20)$ \\
\hline \multirow[t]{2}{*}{ Broad Group*After 1998} & -0.07 & & -0.10 & & 0.07 & & $0.98 * * *$ & & -0.07 & \\
\hline & $(0.11)$ & & $(0.10)$ & & $(0.10)$ & & $(0.37)$ & & $(0.12)$ & \\
\hline \multicolumn{2}{|l|}{ Narrow Group*After1998 } & 0.09 & & 0.08 & & 0.01 & & $2.04 * * *$ & & 0.20 \\
\hline & & $(0.14)$ & & $(0.13)$ & & $(0.16)$ & & $(0.51)$ & & $(0.16)$ \\
\hline \multirow[t]{2}{*}{$\operatorname{Pr}(\mathrm{SSI}) *$ Broad Group } & $-3.48 * * *$ & & -1.60 & & $-4.21 *$ & & $3.44 *$ & & $-3.14 * *$ & \\
\hline & $(1.30)$ & & $(1.35)$ & & $(2.39)$ & & $(1.89)$ & & $(1.34)$ & \\
\hline \multirow[t]{2}{*}{$\operatorname{Pr}(\mathrm{SSI}) *$ Narrow Group } & & $-3.45^{*}$ & & -1.54 & & $-5.83 * *$ & & 2.78 & & $-3.40 *$ \\
\hline & & $(1.85)$ & & $(1.81)$ & & $(2.43)$ & & $(2.26)$ & & $(1.82)$ \\
\hline \multirow[t]{2}{*}{ Pr(SSI)*Broad Group*After 1996} & $5.40 * * *$ & & $3.68 *$ & & 2.72 & & -0.37 & & $5.99 * * *$ & \\
\hline & $(1.94)$ & & $(2.03)$ & & $(3.24)$ & & $(2.88)$ & & $(1.99)$ & \\
\hline \multicolumn{2}{|l|}{ Pr(SSI)*Narrow Group*After1996 } & $5.53 * *$ & & 3.38 & & 5.18 & & 3.52 & & $8.44 * * *$ \\
\hline & & $(2.74)$ & & $(2.70)$ & & $(3.76)$ & & $(3.89)$ & & $(2.71)$ \\
\hline Pr(SSI)*Broad Group*After 1998 & -0.57 & & -1.25 & & 2.75 & & $-4.62 *$ & & -1.23 & \\
\hline
\end{tabular}




\begin{tabular}{|c|c|c|c|c|c|c|c|c|c|c|}
\hline & $(1.71)$ & & $(1.73)$ & & $(2.82)$ & & $(2.81)$ & & $(1.77)$ & \\
\hline \multicolumn{2}{|l|}{$\operatorname{Pr}(\mathrm{SSI}) *$ Narrow Group*After 1998} & -2.79 & & -3.19 & & 1.31 & & -9.62 & & $-5.02 * *$ \\
\hline & & $(2.15)$ & & $(2.12)$ & & $(3.62)$ & & $(3.75)$ & & $(2.23)$ \\
\hline DDD $1997-1998$ v. $1994-1996^{B}$ & $\begin{array}{l}0.130 * * \\
(0.055)\end{array}$ & $\begin{array}{r}0.130 * * \\
(0.058)\end{array}$ & $\begin{array}{c}0.088^{* *} \\
(0.044)\end{array}$ & $\begin{array}{r}0.080 \\
(0.050) \\
\end{array}$ & $\begin{array}{c}0.023 \\
(0.034)\end{array}$ & $\begin{array}{r}0.033 \\
(0.021) \\
\end{array}$ & $\begin{array}{l}-0.069 \\
(0.046)\end{array}$ & $\begin{array}{r}-0.074 \\
(0.054)\end{array}$ & $\begin{array}{c}0.136 * * \\
(0.060)\end{array}$ & $\begin{array}{r}0.193^{* * *} \\
(0.065)\end{array}$ \\
\hline DDD $1999-2002$ v. $1994-1996^{B}$ & $\begin{array}{l}0.108 * * * \\
(0.036)\end{array}$ & $\begin{array}{r}0.053 \\
(0.052) \\
\end{array}$ & $\begin{array}{c}0.057 \\
(0.035)\end{array}$ & $\begin{array}{r}-0.001 \\
(0.048) \\
\end{array}$ & $\begin{array}{c}0.034^{* *} \\
(0.017)\end{array}$ & $\begin{array}{r}0.039 * * \\
(0.018) \\
\end{array}$ & $\begin{array}{l}-0.041 \\
(0.033)\end{array}$ & $\begin{array}{r}-0.023 \\
(0.038) \\
\end{array}$ & $\begin{array}{c}0.095^{* *} \\
(0.040)\end{array}$ & $\begin{array}{r}0.070 \\
(0.047) \\
\end{array}$ \\
\hline DDD $1999-2002$ v. $1997-1998^{B}$ & $\begin{array}{l}-0.022 \\
(0.043) \\
\end{array}$ & $\begin{array}{r}-0.076 \\
(0.055) \\
\end{array}$ & $\begin{array}{l}-0.031 \\
(0.041) \\
\end{array}$ & $\begin{array}{c}-0.081 * \\
(0.049) \\
\end{array}$ & $\begin{array}{c}0.011 \\
(0.017)\end{array}$ & $\begin{array}{r}0.006 \\
(0.020) \\
\end{array}$ & $\begin{array}{c}0.029 \\
(0.041) \\
\end{array}$ & $\begin{array}{r}0.052 \\
(0.048) \\
\end{array}$ & $\begin{array}{l}0.041 \\
(0.048) \\
\end{array}$ & $\begin{array}{r}-0.123^{* *} \\
(0.055) \\
\end{array}$ \\
\hline
\end{tabular}

NOTES: Based on logit models using propensity score-weighted data to match characteristics in the pre-period. Robust, Huber-White corrected SEs shown in ( ) correct for correlation within sampling units. $*=$ p-value $<=.10, * *<=.05, * * *<=.01$. Logit models also include controls for race-gender specific national unemployment rate, national arrest rate per 100,000 and national incarceration rate per 100,000 (coefficients not shown). Analyses are based on a sample size of 156,041. ${ }^{\mathrm{B}}$ Because the coefficients in the model are on a nonlinear scale, for ease of interpretation, we present the calculation of the triple differences in predicted probabilities obtained based on coefficients from the logit models above: DDD $=\{($ Post-Treatment rate- Pre-Treatment rate $)-($ Post-Control rate- Pre-

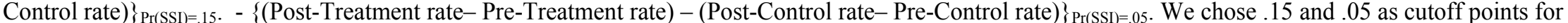
calculating DDD estimates since these span values of the Pr(SSI) that we observe in our data. Standard errors on DDD estimates are bootstrapped using 100 replications. 


\begin{tabular}{|c|c|c|c|c|c|c|c|c|c|c|}
\hline \multicolumn{11}{|c|}{ Appendix Table 5: Health Care Utilization and Arrests in Last Year, Logit Models } \\
\hline & \multicolumn{2}{|l|}{ ER Visit } & \multicolumn{2}{|c|}{ Hospital Adminission } & \multicolumn{2}{|c|}{ Psychiatric Visit } & \multicolumn{2}{|c|}{ Psych. Admission } & \multicolumn{2}{|c|}{ Arrested/booked } \\
\hline \multirow[t]{2}{*}{ Pr(SSI) (1994-1996) } & $5.42 * * *$ & $4.54 * * *$ & $7.55^{* * *}$ & $7.21 * * *$ & $8.00^{* * *}$ & $8.32 * * *$ & $11.57^{* * *}$ & $11.78^{* * *}$ & 2.14 & 1.95 \\
\hline & $(0.61)$ & $(0.71)$ & $(0.80)$ & $(0.88)$ & $(1.10)$ & $(1.28)$ & $(1.88)$ & $(2.35)$ & $(2.27)$ & $(1.95)$ \\
\hline \multirow[t]{2}{*}{ After 1996} & $-0.28 * * *$ & $-0.21 * *$ & -0.01 & 0.07 & $-0.30^{*}$ & $-0.39^{*}$ & -0.13 & -0.03 & -0.11 & 0.02 \\
\hline & $(0.09)$ & $(0.10)$ & $(0.12)$ & $(0.17)$ & $(0.18)$ & $(0.21)$ & $(0.47)$ & $(0.54)$ & $(0.28)$ & $(0.33)$ \\
\hline \multirow[t]{2}{*}{ After 1998} & $0.24 * * *$ & $0.21 * *$ & $0.34 * * *$ & $0.36^{* *}$ & -0.12 & -0.08 & & & $1.41^{* * *}$ & $1.14^{* * *}$ \\
\hline & $(0.08)$ & $(0.10)$ & $(0.11)$ & $(0.15)$ & $(0.18)$ & $(0.21)$ & & & $(0.18)$ & $(0.20)$ \\
\hline \multirow[t]{2}{*}{ Pr(SSI)*After 1996} & 0.09 & -0.62 & 0.37 & 1.15 & 2.15 & 1.93 & 2.62 & 5.25 & 0.69 & -2.51 \\
\hline & $(0.98)$ & $(1.06)$ & $(1.17)$ & $(1.29)$ & $(1.55)$ & $(1.80)$ & $(4.08)$ & $(3.83)$ & $(3.08)$ & $(2.71)$ \\
\hline \multirow[t]{2}{*}{$\operatorname{Pr}(\mathrm{SSI}) *$ After 1998} & -0.39 & 0.28 & -0.62 & -1.60 & $-2.62^{* *}$ & $-3.42 * * *$ & & & 1.51 & $3.53^{*}$ \\
\hline & $(0.79)$ & $(0.91)$ & $(1.01)$ & $(1.15)$ & $(1.27)$ & $(1.29)$ & & & $(2.32)$ & $(2.04)$ \\
\hline \multirow[t]{2}{*}{ Broad Substance Abuser Group } & $0.15^{*}$ & & $-0.20^{*}$ & & $0.24^{*}$ & & $0.69 * *$ & & $1.37^{* * *}$ & \\
\hline & $(0.08)$ & & $(0.12)$ & & $(0.14)$ & & $(0.34)$ & & $(0.14)$ & \\
\hline \multicolumn{2}{|l|}{ Narrow Substance Abuser Group } & $0.25^{* * *}$ & & -0.07 & & $0.54 * * *$ & & $1.28^{* * *}$ & & $1.55^{* * *}$ \\
\hline & & $(0.09)$ & & $(0.15)$ & & $(0.15)$ & & $(0.38)$ & & $(0.16)$ \\
\hline \multirow[t]{2}{*}{ Broad Group*After 1996} & 0.02 & & 0.13 & & 0.35 & & -0.07 & & 0.15 & \\
\hline & $(0.13)$ & & $(0.17)$ & & $(0.24)$ & & $(0.55)$ & & $(0.21)$ & \\
\hline \multicolumn{2}{|l|}{ Narrow Group*After 1996} & -0.07 & & 0.17 & & 0.26 & & -0.04 & & -0.09 \\
\hline & & $(0.15)$ & & $(0.21)$ & & $(0.28)$ & & $(0.55)$ & & $(0.21)$ \\
\hline \multirow[t]{2}{*}{ Broad Group*After 1998} & 0.08 & & 0.15 & & 0.16 & & & & $-0.39^{* *}$ & \\
\hline & $(0.10)$ & & $(0.16)$ & & $(0.21)$ & & & & $(0.18)$ & \\
\hline \multicolumn{2}{|l|}{ Narrow Group*After 1998} & 0.08 & & $0.37 * *$ & & 0.28 & & & & $-0.36^{*}$ \\
\hline & & $(0.13)$ & & $(0.18)$ & & $(0.24)$ & & & & $(0.19)$ \\
\hline \multirow[t]{2}{*}{$\operatorname{Pr}(\mathrm{SSI}) *$ Broad Group } & -1.70 & & 1.23 & & 1.44 & & 1.37 & & -0.48 & \\
\hline & $(1.28)$ & & $(1.76)$ & & $(1.70)$ & & $(3.66)$ & & $(2.69)$ & \\
\hline \multirow[t]{2}{*}{$\operatorname{Pr}(\mathrm{SSI}) *$ Narrow Group } & & -1.43 & & 2.07 & & 0.77 & & -0.74 & & -3.03 \\
\hline & & $(1.55)$ & & $(2.20)$ & & $(2.09)$ & & $(4.56)$ & & $(2.40)$ \\
\hline \multirow[t]{2}{*}{ Pr(SSI)*Broad Group*After 1996} & 1.56 & & 0.47 & & -3.64 & & 3.19 & & -0.12 & \\
\hline & $(2.11)$ & & $(2.18)$ & & $(2.77)$ & & $(5.87)$ & & $(3.68)$ & \\
\hline \multicolumn{2}{|c|}{ Pr(SSI)*Narrow Group*After1996 } & 2.59 & & -1.25 & & -3.49 & & -0.36 & & 4.98 \\
\hline & & $(2.61)$ & & $(3.06)$ & & $(3.04)$ & & $(6.20)$ & & $(3.46)$ \\
\hline $\operatorname{Pr}(\mathrm{SSI}) *$ Broad Group*After 1998 & -0.67 & & 0.33 & & 1.35 & & & & 0.84 & \\
\hline
\end{tabular}




\begin{tabular}{|c|c|c|c|c|c|c|c|c|c|c|}
\hline & $(1.92)$ & & $(2.02)$ & & $(2.32)$ & & & & $(2.96)$ & \\
\hline \multicolumn{2}{|l|}{$\operatorname{Pr}(\mathrm{SSI}) *$ Narrow Group*After 1998} & -0.87 & & 0.59 & & 1.69 & & & & -1.75 \\
\hline & & $(2.20)$ & & $(2.42)$ & & $(2.51)$ & & & & $(3.10)$ \\
\hline DDD $1997-1998$ v. $1994-1996^{B}$ & $\begin{array}{l}0.041 \\
(0.053)\end{array}$ & $\begin{array}{c}0.063 \\
(0.060)\end{array}$ & $\begin{array}{c}0.018 \\
(0.041)\end{array}$ & $\begin{array}{l}-0.006 \\
(0.053)\end{array}$ & $\begin{array}{l}-0.042 \\
(0.040)\end{array}$ & $\begin{array}{l}-0.051 \\
(0.060)\end{array}$ & $\begin{array}{c}0.021 \\
(0.029)\end{array}$ & $\begin{array}{c}0.017 \\
(0.039)\end{array}$ & $\begin{array}{c}0.003 \\
(0.015)\end{array}$ & $\begin{array}{c}0.029 \\
(0.026)\end{array}$ \\
\hline DDD 1999-2002 v. 1994-1996 ${ }^{\text {B }}$ & $\begin{array}{l}0.025 \\
(0.034) \\
\end{array}$ & $\begin{array}{c}0.043 \\
(0.043) \\
\end{array}$ & $\begin{array}{c}0.042 \\
(0.029)\end{array}$ & $\begin{array}{c}0.033 \\
(0.045)\end{array}$ & $\begin{array}{l}-0.019 \\
(0.035)\end{array}$ & $\begin{array}{l}-0.021 \\
(0.041)\end{array}$ & & & $\begin{array}{c}0.036 * * \\
(0.016)\end{array}$ & $\begin{array}{c}0.047^{*} \\
(0.026)\end{array}$ \\
\hline DDD 1999-2002 v. 1997-1998 & \begin{tabular}{|l|}
-0.016 \\
$(0.045)$
\end{tabular} & $\begin{array}{l}-0.202 \\
(0.048)\end{array}$ & $\begin{array}{c}0.024 \\
(0.039)\end{array}$ & $\begin{array}{c}0.040 \\
(0.047)\end{array}$ & $\begin{array}{c}0.023 \\
(0.034)\end{array}$ & $\begin{array}{c}0.029 \\
(0.043)\end{array}$ & & & $\begin{array}{c}0.033^{*} \\
(0.019)\end{array}$ & $\begin{array}{c}0.018 \\
(0.025)\end{array}$ \\
\hline
\end{tabular}

NOTES: Based on logit models using propensity score-weighted data to match characteristics in the pre-period. Robust, Huber-White corrected SEs shown in ( ) correct for correlation within sampling units. $*=$ p-value $<=.10, * *<=.05, * * *<=.01$. Logit models also include controls for race-gender specific national unemployment rate, national arrest rate per 100,000 and national incarceration rate per 100,000 (coefficients not shown). Analyses are based on a sample size of 156,041. ${ }^{\mathrm{B}}$ Because the coefficients in the model are on a nonlinear scale, for ease of interpretation, we present the calculation of the triple differences in predicted probabilities obtained based on coefficients from the logit models above: DDD $=\{($ Post-Treatment rate- Pre-Treatment rate $)-($ Post-Control rate- Pre-

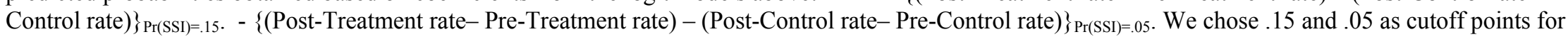
calculating DDD estimates since these span values of the Pr(SSI) that we observe in our data. Standard errors on DDD estimates are bootstrapped using 100 replications. 